\title{
1 Symbiotic signalling is at the core of an endophytic Fusarium solani-legume association
}

2

3 Skiada Vasiliki ${ }^{1}$, Marianna Avramidou ${ }^{1}$, Paola Bonfante ${ }^{2}$, Andrea Genre ${ }^{2}$, Kalliope K. Papadopoulou ${ }^{1 *}$

$5{ }^{1}$ Department of Biochemistry and Biotechnology, University of Thessaly, Biopolis, Larissa, 41500,

6 Greece

$7 \quad 2$ Department of Life Sciences and Systems Biology, University of Torino, Torino, 10125, Italy

8

9 Corresponding author

10 K. K. Papadopoulou

11 Department of Biochemistry and Biotechnology, School of Health Sciences, University of Thessaly

12 Biopolis, Larissa, 41500, Greece

13 Phone: +30 2410 565244, Fax: +30 2410 565290, E-mail: kalpapad@bio.uth.gr

14

Author emails

kalpapad@bio.uth.gr 
38

39

40

\section{Abstract}

Legumes interact with a wide range of microbes in their root system, ranging from beneficial symbionts to pathogens. Symbiotic rhizobia and arbuscular mycorrhizal glomeromycetes trigger a so-called common symbiotic signalling pathway (CSSP), including the induction of nuclear calcium spiking in the root epidermis. In our study, the recognition of an endophytic Fusarium solani strain K in Lotus japonicus induced the expression of LysM receptors for chitin-based molecules, CSSP members and CSSP-dependent genes in L. japonicus. In LysM and CSSP mutant/RNAi lines, root penetration and fungal intraradical progression was either stimulated or limited while FsK exudates are perceived in a CSSP-dependent manner, triggering nuclear calcium spiking in epidermal cells of Medicago truncatula Root Organ Cultures. Our results corroborate that the CSSP is a more common pathway than previously envisaged, involved in the perception of signals from other microbes beyond the restricted group of symbiotic interactions sensu stricto.

\section{Abbreviations:}

AM, Arbuscular Mycorrhizal; AU, airy units; CLSM, Confocal Laser Scanning Microscopy; CO5, pentameric chito-oligosaccharide; CSSP, Common Symbiosis Signalling Pathway; dpi, days post inoculation; Fom, Fusarium oxysporum f. sp. medicaginis; FsK, Fusarium solani strain K; LCOs, lipochitooligosaccharides; Lj, Lotus japonicus; Lysin-motif, LysM; Mt, Medicago truncatula; NF, Nod Factor; PM, plasma membrane; RLK, receptor-like kinase; RLS, rhizobium - legume symbiosis; ROCs,

\section{Root Organ Cultures; wt, wild-type}

(1)

(1)




\section{Introduction}

Plants encounter diverse microorganisms at the root-soil interface, some of which invade the root system and establish detrimental or beneficial associations (Zipfel and Oldroyd, 2017). In this scenario, legumes are unique in their ability to establish two types of mutualistic symbioses: the arbuscular mycorrhizal (AM) and rhizobium-legume (RL) symbiosis. For both interactions, a few plant-directed microbial signals have been characterized so far, and all of them are water soluble chitin-based molecules. Rhizobia produce Nod Factors (NFs), lipo-chitooligosaccharides (LCOs) that are recognized by specific receptor-like kinases (RLKs) (Amor et al., 2003) (Limpens et al., 2003) (Madsen et al., 2003) (Murakami et al., 2018) (Radutoiu et al., 2003), whereas AM fungi release both Nod factor-like Myc-LCOs (Maillet et al., 2011) and short-chain chitin oligomers (Myc-COs) (Genre et al., 2013). The perception of chitin-related molecules in plants is mediated by Lysin-motif (LysM)-RLKs (AntolínLlovera et al., 2014). This is also the case for Nod factors and Myc-LCOs (Fliegmann et al., 2013) (Maillet et al., 2011), whereas specific receptors for Myc-COs remain to be characterized.

Downstream of receptor activation, the intracellular accommodation of both types of symbionts is mediated by a so-called common symbiosis signalling pathway (CSSP) that in Lotus japonicus includes eight genes: the plasma membrane-bound RLK LjSYMRK (MtDMI2 in Medicago truncatula), three nucleoporins (NUP85, NUP133, NENA), the nuclear envelope located cation channels LjCASTOR, and LjPOLLUX (MtDMI1, orthologous to POLLUX), the nuclear calcium and calmodulin-dependent protein kinase $L j \mathrm{CCaMK}$ (MtDMI3), the CCaMK phosphorylation substrate LjCYCLOPS (Kistner et al., 2005) (Charpentier et al., 2008) (Genre and Russo, 2016). Downstream the CSSP lie nodulation/mycorrhization specific transcription factors such as $L j \mathrm{NSP} 1$ and $L j \mathrm{NSP} 2$ (Catoira et al., 2000) (Delaux et al., 2013) (Kalo et al., 2005) (Maillet et al., 2011), and early nodulin genes, like LjENOD2 and LjENOD40 (Glyan'ko, 2018) (Ferguson and Mathesius, 2014) (Takeda et al., 2005). A central element of the CSSP is the triggering of repeated oscillations in nuclear calcium concentration (spiking). In fact, mutants in all CSSP members acting upstream of CCaMK are defective for calcium spiking (Harris et al., 2003) (Miwa et al., 2006) (Parniske, 2008), and the nuclear-localized CCaMK is considered to act as a decoder of the calcium signal, which is translated into phosphorylation events (Yano et al., 2008). Consequently, the induction of nuclear calcium spiking has become of common use as a reliable reporter of CSSP activation by symbiotic microbes or their isolated signals (Wais et al., 2000) (Sieberer et al., 2009) (Chabaud et al., 2011) (Genre et al., 2013) (Charpentier and Oldroyd, 2013). In particular, this approach has been used for the study of AM fungal signalling in both legume and non-legume hosts, using either whole plants or root organ cultures (ROCs) expressing nuclearlocalized calcium-sensing reporters, such as cameleon proteins (Chabaud et al., 2011) (Genre et al., 2013) (Sun et al., 2015) (Carotenuto et al., 2017).

A role for the CSSP in non-symbiotic interactions, has been investigated by many research groups: some propose an (at least partial) involvement (Sanchez et al., 2004) (Sanchez et al., 2005) (Weerasinghe et al., 2005) (Fernandez-Aparicio et al., 2010) (Wang et al., 2012) (Zgadzaj et al., 2015) 
(Zgadzaj et al., 2019), while others do not (Banhara et al., 2015) (Huisman et al., 2015). Nevertheless, little is known about the triggering of nuclear calcium oscillations in such associations, whereas compromised colonization phenotypes by a non-symbiont has not been reported, thus far, for a CSSP mutant.

FsK is a beneficial endophytic isolate of tomato, protecting the plant against root and foliar pathogens (Kavroulakis et al., 2007), spider mites (Pappas et al., 2018), zoophytophagous insects (Garantonakis et al., 2018), and drought (Kavroulakis et al., 2018). We have recently shown that FsK efficiently colonizes legume roots and demonstrates great plasticity throughout colonization (Skiada et al., 2019). Commonalities in the host cell responses between legumes-FsK, and to both symbiotic and pathogenic interactions (Genre et al., 2009) (Skiada et al., 2019), prompted us to investigate the role of the CSSP in this endophytic legume association.

We herein used gene expression analysis and phenotypic screening of mutant/RNAi lines to investigate the role of certain LysM receptors in the Lotus-FsK interaction. We furthermore demonstrate that the expression of L. japonicus markers of AM and/or RL symbiosis is partially altered in the presence of FsK, while two CSSP mutants, ccamk and cyclops, display a delay in fungal colonization. Lastly, we show that the endophyte exudates triggered CSSP-dependent nuclear calcium spiking in the outer root tissues of $M$. truncatula ROCs, which is also observed for exudates from other root-interacting fungi. Overall, our results show that multiple LysM receptors participate in FsK recognition and suggest that the core of the CSSP is also involved in the perception of diffusible signals from non-mycorrhizal fungi.

\section{Results}

\section{FsK inoculation affects the expression of CSSP members and CSSP-regulated genes}

Early FsK colonization of legume roots triggers a number of host cell responses (cytoplasm/ER accumulation, nuclear movement and membrane trafficking at contact site) that are also known to occur in both symbiotic and pathogenic interactions (Skiada et al., 2019). This prompted us to investigate potential similarities with symbiosis-related plant gene expression. We, therefore, analyzed the expression of key CSSP components, such as LjCASTOR, LjCCAMK and LjCYCLOPS, as well as CSSP-regulated symbiosis markers, namely LjNSP1, LjNSP2, LjIPN2, LjENOD4O and LjENOD2. Their regulation was investigated at specific time points during Lotus-FsK interaction, alongside fungal colonization levels (Supplementary Figure 1, 10). The expression of $L j C C a M K$ was marginally but significantly upregulated upon FsK inoculation at very early stages of the interaction (1 dpi), reaching a 2.2-fold upregulation compared to controls at 12 dpi. By contrast, no significant difference was recorded in the expression of $\angle j C A S T O R$ and $L j C Y C L O P S$, or the transcription factors $L j N S P 1$ and LjNSP2, or LjIPN2 (Interacting Protein of NSP2) acting downstream the CSSP, in control and inoculated plants at any time point (Supplementary Figure 1, 10). 
We then tested whether the expression of the symbiosis marker gene LjENOD4O was altered in our Lotus-FsK interaction system. We focused on LjENOD40-1 gene, which is strongly upregulated at very early stages of rhizobium infection, in contrast to the mature nodule marker LjENOD4O-2 (Kumagai et al., 2006). A statistically significant induction of LjENOD40-1 was observed at 2, 4 and 6 dpi (1.6-, 1.9, 1.7-fold, respectively) in inoculated compared to non-inoculated plants. ENOD40 expression coincides with maximum levels of intraradical fungal accommodation (recorded at $4 \mathrm{dpi}$ ) (Supplementary Figure 10). By contrast, we recorded no differences between control and inoculated plants in the expression levels of our second nodulation marker gene, ENOD2, which is expressed in legumes during rhizobial and AM infection and nodule morphogenesis, but not upon fungal pathogen infection (Franssen et al., 1987) (van de Wiel et al., 1990) (van Rhijn et al., 1997).

To summarize, our analyses revealed that FsK colonization was associated with the upregulation of a subset of known symbiosis markers over the course of 12 days post inoculation.

\section{FsK colonization is reduced in CSSP mutants compared to wt plants}

Based on our gene expression results, we investigated the phenotypic differences in FsK colonization of $L$. japonicus CSSP mutants compared to wt plants (Figure 1). We selected mutant lines impaired in CSSP genes acting upstream (symRK-1, castor-1) and downstream of nuclear calcium spiking (ccamk1, cyclops-1). FsK intraradical colonization was quantified via qPCR at 4 and 8 dpi (Figure 1B), when roots are well-colonized by the fungus under our experimental conditions (Supplementary Figure 10). The colonization of symRK-1 and castor-1 mutants was similar to that of wt plants. By contrast, a significant reduction in fungal colonization was observed in both ccamk-1 $(75.17 \%)$ and cyclops-1 (68.82\%) compared to wt plants at 4 dpi. A comparable reduction in fungal intraradical colonization persisted at 8 dpi only in cyclops- 1 plants $(45.77 \%)$.

In conclusion, our phenotypic analysis revealed a significant reduction in FsK colonization only for CSSP mutants for genes that act downstream of nuclear calcium spiking, and the reduction was more evident at earlier time points of the interaction.

\section{Fungal exudates trigger nuclear calcium spiking in wt $M$. truncatula ROC epidermis}

Based on the colonization phenotype in CSSP mutant lines, we then investigated nuclear calcium signals in response to FsK exudate treatment. To this aim, we used wt Medicago truncatula ROCs expressing the nuclear localized cameleon reporters (NupYC2.1), thus allowing FRET based imaging analysis of nuclear calcium responses (Chabaud et al., 2011) (Carotenuto et al., 2019).

We focused on epidermal cells in an area 1-2 cm above the root tip harboring few trichoblasts, because this root zone in model legumes is susceptible to colonization by FsK (Skiada et al., 2019) and is also reported to show the strongest calcium spiking responses to AM fungal exudate (Chabaud et al., 2011). As additional controls, we extended our analysis to include other compatible legume colonizers: the pathogenic Fusarium oxysporum f.sp. medicaginis (Snyder and Hansen, 1940), and Piriformospora 
(Serendipita) indica (Hayes et al., 2014) (Ramírez-Suero et al., 2010), an endophytic fungus with a versatile lifestyle (Verma et al., 1998) (Deshmukh et al., 2006) (Lahrmann et al., 2013).

Exudates from all tested fungi triggered nuclear calcium oscillations in wt $M$. truncatula epidermal cells (Figure 2, Supplementary Figure 2; details about the biological replicates and nuclei screened are presented in Supplementary Table 1). A higher number of cells responded to FsK (70.11\%) or Fom (80.95\%), compared to $P$. indica exudate (43.59\%; Figure 3A). In addition, although the median number of spikes generated in active cells over 30 minutes of recording was comparable for all exudates (5 peaks for FsK and Fom; 4 peaks for P. indica; $p$-value 0.245) (Figure 3B), when we analysed the distribution of peak numbers among the fungal exudates tested in all cells, we recorded differences among peak numbers generated by $P$. indica and FsK or Fom, respectively (p-value $<0.005$ for each pairwise comparison). Thus, differences in the pattern of calcium spikes, expressed as the number of spikes per cell over a period were present.

It has been postulated that information in calcium-mediated signals can be encoded in the amplitude and frequency of the spiking, duration of the response as well as tissue specificity, and this information is responsible for the induction of specific responses (McAinsh and Hetherington, 1998) (Vadassery et al., 2009). Thus, we analyzed (Figure 3C) the oscillatory responses generated by our fungal exudates (Figure 2) by manually calculating the interval between the treatment and the occurrence of the first spike in active cells (lag phase). Differences in median lag phase values of active cells examined per exudate were sharp (127.96 sec for P. indica, $290.32 \mathrm{sec}$ for FsK and $273.12 \mathrm{sec}$ for Fom), and the distribution of lag phase values were statistically different for induced calcium spiking between $P$. indica-FsK and $P$. indica-Fom (p-value $<0.005$ and p-value $<0.05$, respectively).

We also measured the width of each spike in all active cells, estimated as the difference in seconds between the first time point of the upward phase (elevation from the baseline - steady state) and the last time point of the downward phase (return to the baseline - steady state) for each spike. Spikes generated by the 3 fungal exudates had comparable median values (60.22 sec for FsK, $63.38 \mathrm{sec}$ for Fom, 66.47 sec for P. indica; as calculated in the total number of active cells). Analysis of the distribution of spike width values recorded in response to the three exudates, revealed differences among FsK and $P$. indica (p-value $<0.005)$.

Lastly, we analysed the waiting time, i.e. the interval between subsequent peaks. The histogram in Supplementary Figure 4 illustrates the distribution of waiting time autocorrelation values in our populations of spiking profiles. A high number of cells in all treatments demonstrated negative autocorrelation values, indicating that spiking responses to all fungal exudates are in most cases irregular, in analogy to what was described for AM fungal-induced spiking profiles and in contrast with the mostly regular rhizobium-induced calcium spiking signals in the same experimental system (Russo et al., 2013). Statistical analysis showed no dependency between the distribution of waiting time autocorrelation values and the fungal exudate tested. 
Altogether our analysis revealed that the conditions (i.e. constituents of the exudates) that determined the distribution of 1) peak number generated over a certain period of time, 2) lag phase prior to spiking initiation, and, 3) peak width of individual traces in response to the 3 elicitors examined, were not the same. More specifically, $P$. indica- induced calcium spiking had the most profound differences in comparison to Fusaria-induced calcium spiking. Pairwise comparison among the two Fusaria examined, revealed no differences in any of the parameters examined herein.

\section{Nuclear calcium spiking is abolished in Mtdmi2-2 but not in Mtdmi3-1 epidermis}

We then extended our investigation of nuclear calcium signals in ROC epidermal cells of mutants for either MtDMI2 (dmi2-2) and MtDMI3 (dmi3-1), homologs to LjSYMRK and LjCCAMK, respectively (Figure 4, Supplementary Figure 5). In dmi2-2, very few cells were active in any treatment $(10.26 \%$ for FsK, $15 \%$ for Fom, $3.92 \%$ for $P$. indica exudate). By contrast, nuclear calcium spiking was retained in dmi3-1 upon stimulation by the fungal exudates tested (Figure 4A). Furthermore, FsK exudate induced nuclear spiking in a higher percentage of $d m i 3-1$ cells $(81.68 \%)$ compared to wt (70.11\%). The opposite was observed for Fom exudate (69.70\% for $d m i 3-1$ vs $80.95 \%$ for wt), whereas approximately the same percentage of responding cells was recorded in $d m i 3-1$ and wt treated with $P$. indica exudate $(43.50 \%$ for $d m i 3-1$ vs $43.59 \%$ for wt) (Figure 4A).

We then analysed the distribution of peak number in $d m i 3-1$ cells generated by the three fungal exudates (Figure 4B). The median number of spikes for active cells was within similar ranges in all exudates (similar median values to those obtained in the wt lines) (Figure 4B). On the other hand, a significant association was recorded in the peak distribution in total cells (active and non-active) among FsK and $P$. indica exudate (p-value $<0.001$ ), indicating again differences in the number of spikes per cell over a period as observed in wt.

In conclusion, all fungal exudates examined generated intense and repeated nuclear calcium oscillations (spiking). Their activation was dependent on DMI2 (a member of the CSSP acting upstream of calcium oscillations) but not on DMI3 (acting downstream of calcium signalling), suggesting that the core of the CSSP that transduces AM fungal, rhizobial and actinorrhizal signals (Barker et al., 2017) is also involved in the perception of signals from all three non-mycorrhizal fungi.

\section{The biological activity of Fusarium exudates is affected by chitinase and heat treatment}

In an attempt to determine the nature of the factors that triggered nuclear calcium spiking by FsK, we hypothesized that if the triggering compounds were chitin-based molecules, their enzymatic cleavage with chitinase would lead to a decrease in the spiking response (Genre et al., 2013) (Chabaud et al., 2016). For this quest, we also included in the analysis the exudates of Fom, since it belongs in the Fusarium genus, and the two fungal strains produced similar calcium spiking responses in wt and dmi31 cells. Supplementary Figure 6 shows that the percentage of epidermal cells responding to chitinasetreated FsK exudate dropped significantly by $62.86 \%$, and an analogous $44.68 \%$ reduction was observed 
upon chitinase treatment of Fom exudate, compared to their respective control experiments with untreated exudates. As a control for the enzymatic activity of the chitinase solution, we used short-chain COs that are known to elicit calcium spiking in atrichoblasts (Genre et al., 2013). Pre-treatment of $10^{-6}$ M CO5 with chitinase resulted in partial abolishment of nuclear calcium oscillatory response in our experiments (32.12\% reduction; Supplementary Figure 7).

As a second step, we examined the stability of the two exudates under heat treatment. To this aim, we autoclaved FsK and Fom exudates at $120^{\circ} \mathrm{C}$ for $20 \mathrm{~min}$. Again, the reduction in the percent of cells responding to heat-treated exudates as compared to the non-treated ones was more severely affected for FsK $(55.92 \%)$ than Fom $(14.22 \%)$. A prolonged heat treatment of 60 min did not reduce further the activity of FsK exudates (56.70\% reduction in responding epidermal cells).

In short, our tests suggested that the active molecules present in FsK and Fom exudates include both chitinase- and heat-sensitive compounds. Furthermore, the observed differences in the reduction of the activity between heat-treated FsK and Fom exudates suggests that the molecules that trigger a comparable nuclear calcium spiking pattern are different in the two fungal species.

\section{Reaching the pathway backwards: involvement of LysM-RLKs in Lotus japonicus response}

Our results on FRET-based analysis of nuclear calcium changes in wt ROC cells upon chitinase- treated FsK exudate, prompted us to investigate the role of members of the LysM RLK gene family in LotusFsK interaction. We focused on genes that are regulated upon chitin/fungal treatment (Fuechtbauer et al., 2018) (Lohmann et al., 2010) (Rasmussen et al., 2016), and followed their transcriptional regulation over time during Lotus root colonization by FsK. More specifically, we investigated the transcript levels of 6 LjLys genes: Lys6, Lys11, Lys12, Lys13, Lys14, Lys20 (Supplementary Figure 8, 10). Four LysM genes were transcriptionally regulated during the interaction with FsK: Lys6 had a statistically significant upregulation (1.5-fold) at $4 \mathrm{dpi}$, which correlates with maximal fungal presence within plant tissues at this time point (Supplementary Figure 10); Lys13 was upregulated from 2 dpi onwards, and Lys 14 is upregulated only at late stages of the interaction (12 dpi). Lys 12 and Lys20 expression was not altered in the presence of FsK, while Lys11 transcript levels were very low in both control and inoculated tissues, under our experimental conditions.

To further investigate the possible role of differentially expressed LysM genes in Lotus-FsK interaction, we compared FsK colonization levels between wt and mutant lines impaired in LysM genes that were also, transcriptionally affected. Ljlys6-1 displayed significantly higher FsK colonization levels at 4dpi compared to wt plants. Since mutant lines for LjLys 13 and LjLys 14 were not available, we opted for the generation of silenced hairy-root lines, to examine the role of these genes in FsK colonization. We introduced an RNA-hairpin construct targeting both Lys 13 and Lys 14 into L. japonicus roots, using the Agrobacterium rhizogenes-mediated hairy root transformation method. We obtained 7 individual plants showing $70 \%$ to $100 \%$ reduction in Lys 13 relative transcript levels and 66 to $100 \%$ reduction in Lys 14 transcript levels, compared to empty vector-transformed controls (Supplementary Figure 8). More 
specifically, Lys13 was silenced in all selected plant lines (L3, L11, L14, L17, L26, L27, L47), while only four lines were also silenced for Lys14 (L11, L17, L27, L47). All Lys13/14 silenced lines demonstrated statistically significantly lower levels of intraradical FsK colonization when compared to control plants (Figure 5C, p-value $=0.078$ ). Finally, two more available mutant lines, Ljlys 12-3 and the triple mutant Ljnfrlnfr5lys 11, were included for comparison, since Lys12 and Lys11 expression levels were not affected by the presence of the endophyte. The defect in $N F$ receptors in the triple mutant was not expected to have an effect on FsK colonization. Ljlys12-3 displayed significantly higher FsK colonization levels at $4 \mathrm{dpi}$, whereas the triple mutant was colonized to levels similar to those recorded in wt plants (Figure 5B).

\section{Discussion}

\section{Intraradical accommodation of an endophytic fungus is controlled by multiple LysM receptors}

Chitin represents the most ancestral structural polysaccharide in the fungal cell wall (Gow et al., 2017), and most fungi possess chitin synthase enzymes. This was recently, also, shown for oomycetes (Fuechtbauer et al., 2018) (Gibelin-Viala et al., 2019), even though their cell walls primarily consist of $\beta$-glucans (Mélida et al., 2013). Chitosaccharides of variable degree of polymerization, produced either by enzymatic cleavage of the long crystalline chitin, or synthesized anew, are considered as Microbe Associated Molecular Patterns (MAMPs), able to trigger symbiotic signalling (as is the case of short chain COs) (Genre et al., 2013), or immune responses (as is the case of longer-chain COs, $d p=6-8 \mathrm{~N}$ acetyl glucosamine) (Stacey and Shibuya, 1997) (Kouzai et al., 2014) (Liang et al., 2014). As regards the receptors of chitinaceous signal molecules from symbionts, highly specific ones have been identified for the NF and Myc LCOs (Amor et al., 2003) (Radutoiu et al., 2003) (Limpens et al., 2003) (Madsen et al., 2003) (Maillet et al., 2011) (Fliegmann et al., 2013) (Murakami et al., 2018). Recent work on structurally related molecules from pathogenic fungi has shown that very similar LysM-RLKs in legumes enable discrimination between chitin perception and perception of NFs (Bozsoki et al., 2017). FsK exudates comprise of, at least partially, chitin-based molecules of unknown degree of polymerization, while heat-labile molecules must also be present. Characterization of the nature of FsK triggering compounds will require substantially additional research but it is notable that heat treatment did not affect the AM fungal exudate activity (Navazio et al., 2007). As anticipated, certain LysM genes (Lys6, Lys13, Lys14) are regulated in Lotus-FsK interaction, further implying that chitin-based molecules produced by the fungus are recognized by the plant. Two LysM genes, Lys 13 and Lys 14 positively control FsK intracellular accommodation and may act as entry receptors of FsK successful passage through the rhizodermis in the legume root. On the contrary, LjLYS6, and perhaps LYS12 may act as balancing receptors, controlling fungal intraradical proliferation, at the post initial infection stages. This role has already been assigned to LYS6 and LYS12 receptors, in interaction of legumes with pathogenic fungi (Bozsoki et al., 2017) (Fuechtbauer et al., 2018). 
In the Lotus-FsK system, we could detect a phenotype in terms of fungal intraradical accommodation in all available plant lines mutated in $L y s M$ genes, which are, also, transcriptionally affected by FsK. These RLKs could play a role at both early and late stages of the interaction. Assessing the spatial expression of these genes during FsK progression as well as a putative triggering of immune responses will provide further insight in such roles for the accommodation of the endophytic fungus.

\section{A very common symbiosis signalling pathway}

Structural similarities between chitin-based elicitors from either symbiotic or non-symbiotic microbes raise questions about how plants distinguish friend from foe (Zipfel and Oldroyd, 2017). We investigated the role of the CSSP in establishing an endophytic association, making use of the LotusFsK system (Skiada et al., 2019). Our results indicate an unparalleled involvement of the CSSP in LotusFsK association.

Transcriptional reprogramming of CSSP genes, as well as genes acting downstream of it, have been originally described for RL and AM symbiosis. Apart from symbiotic associations in legumes, the involvement of the CSSP in plant associations has been studied in non-symbiotic bacteria in legumes (Sanchez et al., 2005); in legume-parasitic root-knot nematodes (Weerasinghe et al., 2005); and in the successful nodulation of the actinorrhizal plant Casuarina glauca by its symbiont, Frankia sp., in which a functional LjSYMRK (Gherbi et al., 2008) as well as a functional CCaMK (Svistoonoff et al., 2013) are required. Recently, L. japonicus symbiosis genes were shown to structure the root microbiota, as revealed by CSSP mutant analysis (Zgadzaj et al., 2019). In our experimental system, among the genes examined, those acting upstream CCaMK had no effect on FsK accommodation in Lotus roots and were dispensable for determination of FsK colonization levels. In fact, the non-nodulating and nonmycorrhizal symRK-1 and castor-1 mutants (Schauser et al., 1998) (Wegel et al., 1998) (Bonfante et al., 2000) (Novero et al., 2002) (Stracke et al., 2002), displayed a wt-like phenotype in terms of intraradical FsK colonization.

Downstream the nuclear envelope cation channel in the CSSP lies symbiotic calcium spiking (Genre and Russo, 2016). The calcium ion is a universal second messenger in numerous plant signalling pathways. On one hand, cytoplasmic calcium oscillations constitute a general plant cell response to abiotic and biotic stimulation (Knight et al., 1997) (Aldon et al., 2018). More specifically, cytosolic calcium signals have been reported upon perception of symbiotic signals (Navazio et al., 2007), fungal elicitors like chitin and $\beta$-glucans (Mithöfer et al., 1999), cell wall fractions and exudates of endophytic fungi (Vadassery et al., 2009) (Johnson et al., 2018). On the other hand, the generation of nuclear and perinuclear calcium oscillations have been shown to trigger specific plant responses. They occur upon abiotic stimulation (Lachaud et al., 2010) (van der Luit et al., 1999), rhizobial and AM fungi perception (Ehrhardt et al., 1996) (Chabaud et al., 2011), perception of Frankia signals by actinorrhizal plants (Chabaud et al., 2016), and perception of flagellin (flg22), oligosaccharides and proteins leading to necrosis in Nicotiana sp cells (Lecourieux et al., 2005). Our results show that FsK exudates trigger 
periodic calcium oscillations in the nucleus of $M$. truncatula ROCs harbouring nuclear-targeted cameleon reporters (Sieberer et al., 2009). The suppression of this response in $d m i 2-2$ and its persistence in dmi3-1 mutants, strongly suggests that FsK-triggered calcium signals are acting within the CSSP, in analogy to what has been observed for the response to AM fungi and rhizobia (Wais et al., 2000) (Chabaud et al., 2011) (Genre et al., 2013). To the best of our knowledge, there are no previous reports of nuclear calcium oscillations upon compatible, non-symbiotic legume-microbe interactions that are CSSP-dependent. M. truncatula epidermal cells respond to oomycete cell wall fractions by nuclear calcium oscillations but only in a CSSP-independent manner (Nars et al., 2013). This unprecedented conclusion opens a broad field of discussion about the role of the CSSP outside the restricted group of symbiotic interactions sensu stricto.

Indeed, a comparison of nuclear calcium oscillations as a response to FsK exudate with calcium signatures in response to symbiotic factors revealed possible analogies: the patterns recorded in our study resemble those triggered by CO4/AM fungal exudate for their relatively irregular peak distribution. In addition, the average peak width of $\sim 60 \mathrm{sec}$ recorded for FsK, is closer to the 71-100 sec interval for significant peaks as response to Nod factors than to the much shorter 24-36 sec interval observed for mycorrhizal factors (Kosuta et al., 2008). Furthermore, by employing the exudates from two additional fungal species as external controls - the pathogenic Fusarium oxysporum f. sp. medicaginis and the non-mycorrhizal mutualist $P$. indica - we observed comparable nuclear calcium spiking profiles that are CSSP-dependent.

Generation of nuclear calcium oscillations by multiple fungal strains should not be a surprise. Chitinbased molecules are secreted and/or deposited by fungi at the proximity of the interacting plant cell surface. These molecules are structurally related to rhizobial LCOs, as well as Myc COs/LCOs, which are able to activate nuclear calcium spiking in host plants (Ehrhardt et al., 1996) (Sieberer et al., 2009) (Chabaud et al., 2011). Reported symbiotic calcium spiking inducing signals are therefore primarily chitinaceous and the only currently known exception, to our knowledge, is the case of Frankia symbiotic factors able to elicit NIN (Nodule Inception) gene activation and nuclear calcium spiking on roots of the actinorrhizal plant Casuarina glauca. Frankia factors are composed of hydrophilic compounds that are resistant to chitinase digestion (Chabaud et al., 2016).

The placement of nuclear calcium spiking at the core of Lotus-FsK signalling pathway(s) is supported by CSSP gene expression and phenotyping of mutants impaired in genes acting downstream the nuclear calcium spiking response. LjCCAMK (MtDMI3), the gene encoding the kinase responsible for deciphering nuclear calcium signals (Lévy et al., 2004), was marginally upregulated both at early and relatively late time points of the interaction. CCaMK activation at very early stages of the interaction is of interest, because this gene acts at the core of the signal transduction process. Induction of CCaMK at late stages of the interaction, is perhaps associated to fungal progression within host tissues at these stages. Interestingly, $\mathrm{LJCCAMK}$ expression is only marginally affected by $M$. loti inoculation (Tirichine 
et al., 2006), suggesting that this calcium-activated enzyme is differentially involved in the two interactions.

An impaired phenotype with lower colonization levels was recorded in both ccamk-1 and cyclops- 1 mutants, genes acting downstream the calcium spiking response. Interestingly, a comparable delay in nodulation and the occasional and late colonization by AMF (delayed and reduced arbuscule formation) has been reported for the ccamk-1 weak allele (Schauser et al., 1998) (Demchenko et al., 2004), suggestive of a partial functioning of the truncated protein. Alternatively, at these later time points, and possibly due to fungal overload, the necessity for signal deciphering through CCaMK, and signal transduction through CYCLOPS, may be bypassed by redundant proteins acting in parallel and/or alternative signalling routes that allow the progression of fungal accommodation even in the absence of key components of the CSSP. In this latter case, colonization proceeds fast and reaches wt levels belatedly.

Summarizing the above, we propose that FsK produces at least two different types of molecules to activate the CSSP: chitosaccharides of unknown degree of polymerization and heat sensitive molecules. FsK colonizes the root of legumes at least via three alternative routes: 1) When all CSSP components are functional, FsK utilizes the pathway by generating nuclear calcium spiking and activating CCaMK, which lies at the core of FsK recognition towards intraradical accommodation; 2) When SYMRK is impaired, calcium spiking does not occur, but FsK is still capable of effectively colonizing the root, possibly by activating CCaMK through a SYMRK- and calcium spiking-independent route.3) When the calcium spiking response is generated but cannot be perceived or transmitted (impaired CCaMK or CYCLOPS) the CSSP is completely abolished, and yet FsK is still able to colonize the legume root, though with less efficiency. We assume that in this case, an unexplored third route allows a belated intraradical fungal accommodation.

By moving 'deeper' into symbiotic signalling, the nodulation- and mycorrhization- specific transcription factors acting downstream the calcium spiking response, LjNSP1 and NSP2 (Maillet et al., 2011) (Delaux et al., 2013) were not affected in our system. Nevertheless, CSSP-regulated genes that act early in nodulation process were induced upon FsK interaction. The constant mild induction of ENOD40 from 4dpi onwards suggest a possible implication of this nodulin gene in FsK accommodation process. ENOD4O is an early nodulin gene induced in legume tissues upon NF/chitin pentamer treatment (Minami et al., 1996), during AM infection (van Rhijn et al., 1997) and it is linked to symbiotic (nodule formation) and non-symbiotic organogenetic processes (i.e. lateral root formation) in legumes (Papadopoulou et al., 1996). ENOD40 is also regulated by cytokinin (van Rhijn et al., 1997). One can speculate that the rapid and sustained expression of ENOD4O is linked to the preparation of root tissues for FsK accommodation: as a filamentous fungus that grows rapidly within plant tissues, FsK intracellular growth varies from partial to full occupation of the host cell-, involving the rearrangement of plant membranous materials and vesicular activity at infection sites and possibly the assembly of a perifungal membrane system that preserves host cell integrity for a limited time (Skiada 
et al., 2019). In this frame, plant cells may have to expand, and perhaps divide. Cortical cell division was also recently linked to AM symbiosis (Russo et al., 2018). Analysing the hormonal balance in FsKlegume system during such initial events is expected to shed light on the establishment of this legumeendophyte association.

\section{Conclusion}

In the present study we have shown that multiple LysM receptors that perceive chitin molecules play a role during FsK recognition by the legume plant, and act either as positive or balancing regulators of fungal progression within the root. We furthermore show that the CSSP, so far known to be triggered upon microbial symbiont/symbiotic factor perception to allow intracellular accommodation in legume roots, is also utilized by fungal legume-interacting microbes, with a primary focus on the endophytic Fusarium solani strain K. This conclusion suggests that alternative upstream routes - specific to FsK and possibly other microbes - are involved in the activation of the CSSP central core beside rhizobial, mycorrhizal and actinorrhizal factor receptors. The positive regulation of fungal accommodation may be further controlled at steps downstream the calcium spiking response. Our results contribute to the emerging notion that the CSSP is not a sole feature of symbiotic interactions of legumes. It is intriguing and far more perplexing that the question as to how legumes discriminate between two microbes by activating one single pathway should be extended to other interacting microbes as well.

\section{Materials and methods}

\section{Plant materials}

L. japonicus wt plants and the CSSP mutant lines symrk-1, castor-1, sym15-1 (ccamk-1), sym6-1 (cyclops-1) as well as the LysM mutant lines lys6-1, lys12-3 and the triple mutant nfrinfr5lys11 were used for phenotypic screening of FsK intraradical abundance. All mutant lines were kindly provided by Associate Prof Simona Radutoiu (Department of Molecular Biology and Genetics - Plant Molecular Biology, Aarhus, Denmark). The plants were chemically scarified and grown in Petri dishes as described previously (Skiada et al., 2019) until seedlings transplantation to magenta boxes. L. japonicus wt plants (ecotype 'Gifu') were used for gene expression analysis experiments. M. truncatula ROC lines and the CSSP mutant ROC lines dmi2-2 and dmi3-1, expressing the 35S:NupYC2.1 construct (Sieberer et al., 2009) were obtained previously (Chabaud et al., 2011). An apical segment deriving from each ROC line was routinely transferred to square Petri dishes containing $\mathrm{M}$ medium (Bécard and Fortin, 1988) and placed in a vertical position at $26^{\circ} \mathrm{C}$ in the dark, to favour the development of a regular, fishbone-shaped root system (Chabaud et al., 2002). Segments derived from ROCs were used for calcium spiking bioassays upon fungal exudates and chitooligosaccharide treatment. 


\section{Fungal materials}

Fusarium solani strain K (FsK) (Kavroulakis et al., 2007) was routinely cultured in Potato Dextrose Agar (PDA) medium and conidia were isolated as previously described (Skiada et al., 2019). Fungal conidia were used as inoculum for phenotypic profiling of all mutant lines and for gene expression analysis experiments. Fusarium oxysporum f. sp. medicaginis (Fom, BPIC 2561) (Snyder and Hansen, 1940) was kindly provided by Benaki Phytopathological Institute (Benaki phytopathological Institute Collection, BPIC), Attiki, Greece. Piriformospora indica (MUT00004176) was kindly provided by Mycotheca Universitatis Taurinenesis, Turin, Italy. Fom and $P$. indica were routinely cultured in PDA medium. FsK, Fom and $P$. indica hyphal propagules were used for preparation of fungal exudates for calcium spiking analyses.

\section{Experimental setup for gene expression analysis and phenotypic screening of $L$. japonicus mutants}

L. japonicus seedlings (7-11 days old) were transplanted into magenta boxes (3 plants per magenta) containing sterile sand:vermiculite (3:1) and directly inoculated on the root with $10^{2}$ conidia per plant. Control plants received the same volume of sterile water. The substrate was watered with $30 \mathrm{ml}$ of $\mathrm{M}$ medium (Boisson-Dernier et al., 2001) prior to transplantation, in both treatments. Magenta boxes were transferred in a growth chamber $\left(16 \mathrm{~h}\right.$ light $/ 8 \mathrm{~h}$ dark photoperiod, $\left.22^{\circ} \mathrm{C}\right)$.

For gene expression analysis, plants were harvested at 1,2, 4, 6, 12 days post inoculation (dpi), washed $5 \mathrm{x}$ with sterile water to remove the excess extraradical mycelium, root tissues were collected, flash frozen under liquid nitrogen and kept at $-80^{\circ} \mathrm{C}$ until subsequent DNA/RNA isolation. Four (4) biological replicates were assessed for each treatment, with each replicate consisting of 3 individual plants. Estimation of intraradical abundance and gene expression analysis were performed as described below. For phenotypic profiling, wt and CSSP mutants were harvested at 4 and 8 dpi and LysM mutants were harvested at 4 dpi. Different batches of wt L. japonicus plants were assessed for CSSP or for LysM mutants. Harvested plants were surface sterilized $(1 \% \mathrm{v} / \mathrm{v} \mathrm{NaOCl})$, washed $5 \mathrm{x}$ with sterile water, root tissues were collected, frozen under liquid nitrogen and kept at -20 until subsequent DNA isolation. Five (5) biological replicates were assessed for each treatment, with each replicate consisting of 3 individual plants. Estimation of intraradical fungal abundance was performed as described below.

\section{Agrobacterium rhizogenes-mediated hairy-root transformation and plant inoculation with FsK}

A 176 bp fragment specific of Lys13/Lys14 genes (100\% nucleic acid similarity in both genes) was amplified by PCR using specific primers (Supplementary Table 2) and cDNA derived from RNA extracted from $L$. japonicus root tissues as a template, and was introduced in the pUBI-GWS-GFP vector (Maekawa et al., 2008) in order to generate an RNA-hairpin expression construct targeting both Lys13/Lys14. The binary vector was transformed into Agrobacterium rhizogenes LBA1334 and used for generation of L. japonicus hairy roots as described previously (Krokida et al., 2013). Control plants 
were transformed with the empty pUBI-GWS-GFP. Regenerated hairy roots were screened for GFP fluorescence, non-transformed roots excised, and the presence of the hairpin expressing T-DNA was verified by PCR using primers specific for the GFP CDS.

Plants with regenerated hairy roots (16 days old) were transferred into pots containing sterile sand:vermiculite (3:1) substrate, in a growth chamber (16h light/8h dark photoperiod, $\left.22^{\circ} \mathrm{C}\right)$. Plants were alternately watered with distilled water or Hoagland medium. Two days post transfer plants were inoculated with $10^{2} \mathrm{FsK}$ conidia per root. At 5 dpi, plants were harvested, washed $5 \mathrm{x}$ with sterile water to remove the excess extraradical mycelium, root tissues were collected, flash frozen under liquid nitrogen and kept at $-80^{\circ} \mathrm{C}$ until subsequent DNA/RNA isolation.

Silencing of Lys 13, Lys 14 was verified by gene expression analysis. RNA isolation, cDNA synthesis and qPCR for estimation of Lys13/Lys14 transcript levels was conducted as described below. Based on these results 7 lines were chosen showing reduced expression levels of Lys13, Lys 14 or both. DNA was isolated from the same tissues and $1 \mu \mathrm{l}$ was used for absolute quantification of Fusarium solani ITS gene copy number and therefore estimation of intraradical fungal abundance.

\section{DNA isolation}

L. japonicus root tissues were grounded with a pestle, under the presence of liquid nitrogen, and total DNA was isolated using the CTAB method (Doyle and Doyle, 1987). For quantification of intraradical fungal abundance, the weight of the plant tissue was determined prior to DNA isolation. DNA concentration was determined using Qubit 2.0 fluorometer. $1 \mu$ of the eluted DNA was used as template in qPCR reaction for estimation of intraradical fungal abundance in L. japonicus wt, CSSP and LysM mutant/RNAi lines.

\section{RNA isolation}

Total RNA was extracted using the Isolate II RNA Plant Kit (BIO-52077, BIOLINE) according to manufacturer's instructions. To eliminate genomic DNA carry-over in subsequent reactions, samples were treated with DNase I (18047019, Invitrogen) at $37^{\circ} \mathrm{C}$ for $1 \mathrm{~h}$. Elimination of genomic DNA contamination was verified by PCR, using primers specific for $L j$ UBIQUITIN gene (Supplementary Table 2) and subsequent agarose gel electrophoresis of the PCR products.

\section{Gene expression analysis}

First strand cDNA was synthesized from DNase treated total RNA, using the PrimeScript ${ }^{\text {TM }} 1$ st strand cDNA Synthesis Kit (6110A, Takara). Quantitative real-time RT-PCR (qPCR) was performed using gene-specific primers (Supplementary Table 1) and the fluorescent intercalating dye Kapa SYBR Green (Kapa SYBR FAST qPCR Master Mix Universal, Kapa Biosystems) in a BIORAD CFX Connect ${ }^{\mathrm{TM}}$ Real-Time PCR Detection System. All quantifications were normalized to $L j$ UBIQUITIN 
housekeeping gene. Data were analysed according to (Pfaffl, 2001). Reaction efficiencies were estimated through the free software program LinRegPCR (Ramakers et al., 2003).

\section{Quantification of fungal colonization in $L$. japonicus wt, CSSP, LysM mutant/RNAi lines}

To estimate fungal abundance within root tissues, absolute quantification of $F$. solani ITS or TEFla gene was performed by using a previously constructed standard curve (Skiada et al., 2019). For each experiment, amplification of each sample (standards - unknowns) occurred in a $10 \mu$ reaction mixture containing Kapa SYBR FAST qPCR Master Mix Universal (1x), $200 \mathrm{nM}$ of each primer, and $1 \mu \mathrm{l}$ of DNA, using a thermocycling protocol of $3 \mathrm{~min}$ at $95{ }^{\circ} \mathrm{C} ; 45$ cycles of $15 \mathrm{~s}$ at $95{ }^{\circ} \mathrm{C}, 20 \mathrm{~s}$ at $58{ }^{\circ} \mathrm{C}$, followed by a melting curve to check the specificity of the products. Absolute quantification of unknown samples was estimated as the exact copy concentration of the target gene by relating the CT value to the standard curve. The fungal gene copy numbers of all samples were normalized by ng of total DNA isolated, or by $\mathrm{mg}$ of tissue used to extract DNA, or both. Agarose gel $(1.5 \% \mathrm{w} / \mathrm{v})$ electrophoresis of qPCR products was routinely performed, to verify the amplification of a single fragment of the desired length. Intraradical fungal colonization of L. japonicus control/FsK inoculated plants was estimated by quantification of TEFla fungal gene. qPCR amplification efficiencies were $100.91 \%$ with $\mathrm{r}^{2}$ value of 0.991 and a slope of -3.300 . Intraradical fungal colonization in L. japonicus wt-CSSP mutants, in wt-LysM mutants and wt-RNAi lines was estimated by quantification of ITS fungal gene. qPCR amplification efficiencies were $91.82 \%$ with $\mathrm{r}^{2}$ value of 0.997 and a slope of -3.535 for the CSP mutants, $95.46 \%$ with $\mathrm{r}^{2}$ value of 0.995 and a slope of -3.436 for LysM mutants and $89.7 \%$ with $r^{2}$ value of 0.997 and a slope of -3.598 for the RNAi lines screening.

\section{Preparation of fungal exudates and root treatment}

Exudates of FsK, Fom and P. indica were prepared as previously described (Lace et al., 2015). Briefly, $1 \mathrm{ml}$ of water was distributed in eppendorf tubes and inoculated with fungal hyphae obtained by slightly scrapping with a sterile scalpel the surface of a previous culture of the fungus on Potato Dextrose Agar (PDA). Tubes were incubated for 7 days at $26^{\circ} \mathrm{C}$, the exudate was afterwards recovered with a sterile syringe, filter sterilized ( $0.2 \mu \mathrm{m}$ filters), concentrated 10 -fold using a lyophilizer, and stored at $-20^{\circ} \mathrm{C}$ until further use. Exudates of Gigaspora margarita were prepared as described in (Chabaud et al., 2011). Segments of primary $M t$ wild type and dmi2-2/dmi3-1 mutant ROCs carrying one or two young laterals were placed in a microchamber and treated with $100 \mu \mathrm{l}$ of fungal exudate as described in (Chabaud et al., 2011). For CO5 treatment, aqueous solutions at a final concentration of $10^{-6} \mathrm{M}$ were prepared from a concentrated stock of purified chitin pentamer solution and root explants were treated as above. As negative control, sterile water was used. As positive control, G. margarita germinated spore exudate, or purified COs (degree of polymerization, $n=5$ ) were used. 


\section{Assays performed on fungal exudates and COs}

Chitinase treatment of the G. margarita GSE was performed using $1 \mathrm{mg} \mathrm{ml}^{-1}$ chitinase from Streptomyces griseus (ref C6137; Sigma-Aldrich) in sterile $\mathrm{H}_{2} \mathrm{O}$ for $16 \mathrm{~h}$ at room temperature. Autoclave treatment was performed by autoclaving the exudates $\left(121^{\circ} \mathrm{C}, 1 \mathrm{~atm}\right)$ for $20 \mathrm{~min}$ or for $1 \mathrm{~h}$. Chitinase treated exudates of FsK and Fom were tested for their ability to generate calcium spiking responses on wt NupYC2.1 Mt ROCs epidermis. Autoclave treated exudates of FsK were tested for their ability to generate calcium spiking responses on wt NupYC2.1 Mt ROCs epidermis.

\section{Confocal microscopy for calcium spiking measurements in M. truncatula ROC epidermis}

A FRET-based ratiometric approach (Sieberer et al., 2009) was used to record the relative changes of nuclear calcium concentrations corresponding to Yellow Fluorescent Protein (YFP) to Cyan Fluorescent Protein (CFP) fluorescence intensity changes over time (Miyawaki et al., 1997). Analysis was performed using a Leica TCS SP2 confocal microscope fitted with a long distance x40 waterimmersion objective (HCX Apo 0.80). Measurements were performed and settings were set as previously described (Chabaud et al., 2011). The pinhole diameter was set at 6 airy units. YFP and CFP fluorescence intensities were calculated for each region of interest (each nucleus) using Leica LCS software. Values were then exported to a Microsoft Excel spreadsheet, the YFP/CFP ratio for each time frame was calculated, and ratio values were plotted over time. A graphical representation of FRET ratio was finally generated, which indicated the relative calcium concentration changes in the nucleus over time. Nuclear spiking was examined in all cases in an atrichoblast/low-trichoblast zone located 10-20 $\mathrm{mm}$ from the root tip.

Calcium spiking measurements were furthermore analyzed using CaSA software (Russo et al., 2013). The generation of at least 3 peaks was the threshold for discrimination between responding and nonresponding cells. The total number of epidermal cell nuclei and independent root segments analyzed for each test are reported in the corresponding Figures/Figure legends. CaSA output PNG image files indicating spike initiation and end points, were used to manually calculate peak width and lag phases prior to calcium spiking response initiation in responding nuclei. CaSa output waiting time autocorrelation values were used to generate the corresponding histogram.

\section{Statistical analysis}

Two-way ANOVA followed by Tukey's post-hoc test was used in gene expression analysis data. Student's t-test was used in all pairwise comparisons. One-way ANOVA was used in comparisons between 3 or more independent (unrelated) groups (i.e. analysis of calcium spiking results obtained after plant cells elicitation with the three investigated fungal exudates). The non-parametric Kolmogorov-Smirnov (K-S) two-sample test was used to assess whether data corresponding to a) number of peaks, b) lag phase prior to spiking initiation, c) width of peaks, generated in $M t$ nuclei by the 3 elicitors, are drawn from the same distribution (pairwise comparisons among results from the 3 
elicitors). Pearson's chi squared test was used to test whether the frequency distribution of waiting times autocorrelation values of peaks generated by the 3 fungal exudates are independent. Statistical analyses used are indicated in detail in the corresponding Figures/Figure legends.

\section{Acknowledgement}

We are grateful to Daniela Tsikou for sharing ideas and her suggestions during the initiation of the project, and for reading and commenting on the manuscript; to Constantine Garagounis for his suggestions and contribution in the analysis of hairy roots experiments, and for reading and commenting on the manuscript. We also thank Dimitra Papantoniou for her assistance in the hairy root experiment. This work was partially supported by the Postgraduate Programme 3817 of the Department of Biochemistry and Biotechnology, University of Thessaly, Programme 4757.17 (funded by GGSRT/EU/ NSRF to KKP) and COST Action FA1206 and FA1405 (STSM Grants to VS).

\section{References}

Aldon D, Mbengue M, Mazars C, Galaud JP. 2018. Calcium signalling in plant biotic interactions. Int J Mol Sci 19:1-19. doi:10.3390/ijms19030665

Amor B Ben, Shaw SL, Oldroyd GED, Maillet F, Penmetsa RV, Cook D, Long SR, Dénarié J, Gough C. 2003. The NFP locus of Medicago truncatula controls an early step of Nod factor signal transduction upstream of a rapid calcium flux and root hair deformation. Plant J 34:495-506. doi:10.1046/j.1365-313X.2003.01743.x

Antolín-Llovera M, Petutsching EK, Ried MK, Lipka V, Nürnberger T, Robatzek S, Parniske M. 2014. Knowing your friends and foes - plant receptor-like kinases as initiators of symbiosis or defence. New Phytol 204:791-802. doi:10.1111/nph.13117

Banhara A, Ding Y, Kühner R, Zuccaro A, Parniske M. 2015. Colonization of root cells and plant growth promotion by Piriformospora indica occurs independently of plant common symbiosis genes. Front Plant Sci 6:667. doi:10.3389/fpls.2015.00667

Barker DG, Chabaud M, Russo G, Genre A. 2017. Nuclear $\mathrm{Ca}^{2+}$ signalling in arbuscular mycorrhizal and actinorhizal endosymbioses: on the trail of novel underground signals. New Phytol 214:533538. doi:10.1111/nph.14350

Bécard G, Fortin JA. 1988. Early events of vesicular-arbuscular mycorrhiza formation on Ri T-DNA transformed roots. New Phytol 108:211-218. doi:10.1111/j.1469-8137.1988.tb03698.x

Bonfante P, Genre A, Faccio A, Martini I, Schauser L, Stougaard J, Webb J, Parniske M. 2000. The Lotus japonicus LjSym 4 gene is required for the successful symbiotic infection of root epidermal cells. Mol Plant Microbe Interact 13:1109-20. doi:10.1094/MPMI.2000.13.10.1109

Bozsoki Z, Cheng J, Feng F, Gysel K, Vinther M, Andersen KR, Oldroyd G, Blaise M, Radutoiu S, Stougaard J. 2017. Receptor-mediated chitin perception in legume roots is functionally separable from Nod factor perception. Proc Natl Acad Sci 114:E8118-E8127. 
doi:10.1073/pnas.1706795114

Carotenuto G, Chabaud M, Miyata K, Capozzi M, Takeda N, Kaku H, Shibuya N, Nakagawa T, Barker DG, Genre A. 2017. The rice LysM receptor-like kinase OsCERK1 is required for the perception of short-chain chitin oligomers in arbuscular mycorrhizal signaling. New Phytol 214:1440-1446. doi:10.1111/nph.14539

Carotenuto G, Volpe V, Russo G, Politi M, Sciascia I, de Almeida-Engler J, Genre A. 2019. Local endoreduplication as a feature of intracellular fungal accommodation in arbuscular mycorrhizas. New Phytol 223:430-446. doi:10.1111/nph.15763

Catoira R, Galera C, de Billy F, Penmetsa RV, Journet E-P, Maillet F, Rosenberg C, Cook D, Gough C, Denarie J. 2000. Four Genes of Medicago truncatula Controlling Components of a Nod Factor Transduction Pathway. Plant Cell 12:1647-1665. doi:10.2307/3871180

Chabaud M, Genre A, Sieberer BJ, Faccio A, Fournier J, Novero M, Barker DG, Bonfante P. 2011. Arbuscular mycorrhizal hyphopodia and germinated spore exudates trigger $\mathrm{Ca}^{2+}$ spiking in the legume and nonlegume root epidermis. New Phytol 189:347-355. doi:10.1111/j.14698137.2010.03464.x

Chabaud M, Gherbi H, Pirolles E, Vaissayre V, Fournier J, Moukouanga D, Franche C, Bogusz D, Tisa LS, Barker DG, Svistoonoff S. 2016. Chitinase-resistant hydrophilic symbiotic factors secreted by Frankia activate both $\mathrm{Ca}^{2+}$ spiking and NIN gene expression in the actinorhizal plant Casuarina glauca. New Phytol 209:86-93. doi:10.1111/nph.13732

Chabaud M, Venard C, Defaux-Petras A, Becard G, Barker DG. 2002. Targeted inoculation of Medicago truncatula in vitro root cultures reveals MtENOD11 expression during early stages of infection by arbuscular mycorrhizal fungi. New Phytol 156:265-273. doi:10.1046/j.14698137.2002.00508.x

Charpentier M, Bredemeier R, Wanner G, Takeda N, Schleiff E, Parniske M. 2008. Lotus japonicus CASTOR and POLLUX are ion channels essential for perinuclear calcium spiking in legume root endosymbiosis. Plant Cell 20:3467-79. doi:10.1105/tpc.108.063255

Charpentier M, Oldroyd GED. 2013. Nuclear Calcium Signaling in Plants. Plant Physiol 163:496503. doi:10.1104/pp.113.220863

Delaux P-M, Becard G, Combier J-P. 2013. NSP1 is a component of the Myc signaling pathway. New Phytol 199:59-65. doi:10.1111/nph.12340

Demchenko K, Winzer T, Stougaard J, Parniske M, Pawlowski K. 2004. Distinct roles of Lotus japonicus SYMRK and SYM15 in root colonization and arbuscule formation. New Phytol 163:381-392. doi:10.1111/j.1469-8137.2004.01123.x

Deshmukh S, Hückelhoven R, Schäfer P, Imani J, Sharma M, Weiss M, Waller F, Kogel K-H. 2006. The root endophytic fungus Piriformospora indica requires host cell death for proliferation during mutualistic symbiosis with barley. Proc Natl Acad Sci U S A 103:18450-18457. doi:10.1073/pnas.0605697103 
Doyle JJ, Doyle JL. 1987. A rapid DNA isolation procedure for small quantities of fresh leaf tissue. Phytochem Bull 19:11-15.

Ehrhardt DW, Wais R, Long SR. 1996. Calcium spiking in plant root hairs responding to rhizobium modulation signals. Cell 85:673-681. doi:10.1016/S0092-8674(00)81234-9

Ferguson BJ, Mathesius U. 2014. Phytohormone Regulation of Legume-Rhizobia Interactions. $J$ Chem Ecol 40:770-790. doi:10.1007/s10886-014-0472-7

Fernandez-Aparicio M, Rispail N, Prats E, Morandi D, Garcia-Garrido JM, Dumas-Gaudot E, Duc G, Rubiales D. 2010. Parasitic plant infection is partially controlled through symbiotic pathways. Weed Res 50:76-82. doi:10.1111/j.1365-3180.2009.00749.x

Fliegmann J, Canova S, Lachaud C, Uhlenbroich S, Gasciolli V, Pichereaux C, Rossignol M, Rosenberg C, Cumener M, Pitorre D, Lefebvre B, Gough C, Samain E, Fort S, Driguez H, Vauzeilles B, Beau J-M, Nurisso A, Imberty A, Cullimore J, Bono J-J. 2013. Lipochitooligosaccharidic Symbiotic Signals Are Recognized by LysM Receptor-Like Kinase LYR3 in the Legume Medicago truncatula. ACS Chem Biol 8:1900-1906. doi:10.1021/cb400369u

Franssen HJ, Nap J-P, Gloudemans T, Stiekema W, Van Dam H, Govers F, Louwerse J, Van Kammen A, Bisseling T. 1987. Characterization of cDNA for nodulin-75 of soybean: A gene product involved in early stages of root nodule development. Proc Natl Acad Sci 84:4495-4499. doi:10.1073/pnas.84.13.4495

Fuechtbauer W, Yunusov T, Bozsóki Z, Gavrin A, James EK, Stougaard J, Schornack S, Radutoiu S. 2018. LYS12 LysM receptor decelerates Phytophthora palmivora disease progression in Lotus japonicus. Plant J 93:297-310. doi:10.1111/tpj.13785

Garantonakis N, Pappas ML, Varikou K, Skiada V, Broufas GD, Kavroulakis N, Papadopoulou KK. 2018. Tomato Inoculation With the Endophytic Strain Fusarium solani K Results in Reduced Feeding Damage by the Zoophytophagous Predator Nesidiocoris tenuis. Front Ecol Evol 6:126. doi:10.3389/fevo.2018.00126

Genre A, Chabaud M, Balzergue C, Puech-Pagès V, Novero M, Rey T, Fournier J, Rochange S, Bécard G, Bonfante P, Barker DG. 2013. Short-chain chitin oligomers from arbuscular mycorrhizal fungi trigger nuclear $\mathrm{Ca}^{2+}$ spiking in Medicago truncatula roots and their production is enhanced by strigolactone. New Phytol 198:190-202. doi:10.1111/nph.12146

Genre A, Ortu G, Bertoldo C, Martino E, Bonfante P. 2009. Biotic and abiotic stimulation of root epidermal cells reveals common and specific responses to Arbuscular Mycorrhizal Fungi. Plant Physiol 149:1424-1434. doi:10.1104/pp.108.132225

Genre A, Russo G. 2016. Does a common pathway transduce symbiotic signals in plant-microbe interactions? Front Plant Sci 7:96. doi:10.3389/fpls.2016.00096

Gherbi H, Markmann K, Svistoonoff S, Estevan J, Autran D, Gabor G, Auguy F, Peret B, Laplaze L, Franche C, Parniske M, Bogusz D. 2008. SymRK defines a common genetic basis for plant root endosymbioses with arbuscular mycorrhiza fungi, rhizobia, and Frankia bacteria. PNAS 
105:4928-4932. doi:10.1073/pnas.0710618105

Gibelin-Viala C, Amblard E, Puech-Pages V, Bonhomme M, Garcia M, Bascaules-Bedin A, Fliegmann J, Wen J, Mysore KS, le Signor C, Jacquet C, Gough C. 2019. The Medicago truncatula LysM receptor-like kinase LYK9 plays a dual role in immunity and the arbuscular mycorrhizal symbiosis. New Phytol 0. doi:10.1111/nph.15891

Glyan'ko AK. 2018. Phytohormones and Morphogenesis of Root Nodules and Lateral Roots of a Legume Plant. J Stress Physiol Biochem 14:12-26.

Gow NAR, Latge J-P, Munro CA. 2017. The Fungal Cell Wall: Structure, Biosynthesis, and Function. Microbiol Spectr 5:FUNK-0035-2016. doi:10.1128/microbiolspec.FUNK-0035-2016

Harris JM, Wais R, Long SR. 2003. Rhizobium-Induced calcium spiking in Lotus japonicus. Mol Plant Microbe Interact 16:335-341. doi:10.1094/MPMI.2003.16.4.335

Hayes MW, Stutte GW, Mckeon-bennett M, Murray PG. 2014. Mutualism Within a Simulated Microgravity Environment -Piriformospora indica Promotes the Growth of Medicago truncatula. Gravitational Sp Res 2:21-33.

Huisman R, Bouwmeester K, Brattinga M, Govers F, Bisseling T, Limpens E. 2015. Haustorium Formation in Medicago truncatula Roots Infected by Phytophthora palmivora Does Not Involve the Common Endosymbiotic Program Shared by Arbuscular Mycorrhizal Fungi and Rhizobia. Mol Plant-Microbe Interact 28:1271-1280. doi:10.1094/MPMI-06-15-0130-R Johnson JM, Ludwig A, Furch ACU, Mithöfer A, Scholz S, Reichelt M, Oelmüller R. 2018. The Beneficial Root-Colonizing Fungus Mortierella hyalina Promotes the Aerial Growth of Arabidopsis and Activates Calcium-Dependent Responses That Restrict Alternaria brassicaeInduced Disease Development in Roots. Mol Plant-Microbe Interact 32:351-363. doi:10.1094/MPMI-05-18-0115-R

Kalo P, Gleason C, Edwards A, Marsh J, Mitra RM, Hirsch S, Jakab J, Sims S, Long SR, Rogers J, Kiss GB, Downie JA, Oldroyd GED. 2005. Nodulation Signaling in Legumes Requires NSP2, a Member of the GRAS Family of Transcriptional Regulators. Science (80- ) 308:1786-1789. doi:10.1126/science.1110951

Kavroulakis N, Doupis G, Papadakis IE, Ehaliotis C, Papadopoulou KK. 2018. Tolerance of tomato plants to water stress is improved by the root endophyte Fusarium solani FsK. Rhizosphere 6:77-85. doi:10.1016/j.rhisph.2018.04.003

Kavroulakis N, Ntougias S, Zervakis GI, Ehaliotis C, Haralampidis K, Papadopoulou KK. 2007. Role of ethylene in the protection of tomato plants against soil-borne fungal pathogens conferred by an endophytic Fusarium solani strain. J Exp Bot 58:3853-3864. doi:10.1093/jxb/erm230

Kistner C, Winzer T, Pitzschke A, Mulder L, Sato S, Kaneko T, Tabata S, Sandal N, Stougaard J, Webb KJ, Szczyglowski K, Parniske M. 2005. Seven Lotus japonicus Genes Required for Transcriptional Reprogramming of the Root during Fungal and Bacterial Symbiosis. Plant Cell 17:2217-2229. doi:10.1105/tpc.105.032714 
Knight H, Trewavas AJ, Knight MR. 1997. Calcium signalling in Arabidopsis thaliana responding to drought and salinity. Plant J 12:1067-1078. doi:10.1046/j.1365-313X.1997.12051067.X

Kosuta S, Hazledine S, Sun J, Miwa H, Morris RJ, Downie JA, Oldroyd GED. 2008. Differential and chaotic calcium signatures in the symbiosis signaling pathway of legumes. Proc Natl Acad Sci U $S$ A 105:9823-8. doi:10.1073/pnas.0803499105

Kouzai Y, Nakajima K, Hayafune M, Ozawa K, Kaku H, Shibuya N, Minami E, Nishizawa Y. 2014. CEBiP is the major chitin oligomer-binding protein in rice and plays a main role in the perception of chitin oligomers. Plant Mol Biol 84:519-528. doi:10.1007/s11103-013-0149-6

Krokida A, Delis C, Geisler K, Garagounis C, Tsikou D, Peña-Rodríguez LM, Katsarou D, Field B, Osbourn AE, Papadopoulou KK. 2013. A metabolic gene cluster in Lotus japonicus discloses novel enzyme functions and products in triterpene biosynthesis. New Phytol 200:675-690. doi:10.1111/nph.12414

Kumagai H, Kinoshita E, Ridge RW, Kouchi H. 2006. RNAi knock-down of ENOD40s leads to significant suppression of nodule formation in Lotus japonicus. Plant Cell Physiol 47:11021111. doi:10.1093/pcp/pcj081

Lace B, Genre A, Woo S, Faccio A, Lorito M, Bonfante P. 2015. Gate crashing arbuscular mycorrhizas: In vivo imaging shows the extensive colonization of both symbionts by Trichoderma atroviride. Environ Microbiol Rep 7:64-77. doi:10.1111/1758-2229.12221

Lachaud C, Da Silva D, Cotelle V, Thuleau P, Xiong TC, Jauneau A, Brière C, Graziana A, Bellec Y, Faure J, Ranjeva R, Mazars C. 2010. Nuclear calcium controls the apoptotic-like cell death induced by D-erythro-sphinganine in tobacco cells. Cell Calcium 47:92-100. doi:10.1016/j.ceca.2009.11.011

Lahrmann U, Ding Y, Banhara A, Rath M, Hajirezaei MR, Döhlemann S, von Wirén N, Parniske M, Zuccaro A. 2013. Host-related metabolic cues affect colonization strategies of a root endophyte. Proc Natl Acad Sci USA 110:13965-13970. doi:10.1073/pnas.1301653110

Lecourieux D, Lamotte O, Bourque S, Wendehenne D, Mazars C, Ranjeva R, Pugin A. 2005. Proteinaceous and oligosaccharidic elicitors induce different calcium signatures in the nucleus of tobacco cells. Cell Calcium 38:527-538. doi:10.1016/j.ceca.2005.06.036

Lévy J, Bres C, Geurts R, Chalhoub B, Kulikova O, Duc G, Journet E-P, Ané J-M, Lauber E, Bisseling T, Dénarié J, Rosenberg C, Debellé F. 2004. A Putative Ca\&lt;sup\&gt;2+\&lt;/sup\&gt; and Calmodulin-Dependent Protein Kinase Required for Bacterial and Fungal Symbioses. Science (80- ) 303:1361 LP - 1364. doi:10.1126/science.1093038

Liang Y, Tóth K, Cao Y, Tanaka K, Espinoza C, Stacey G. 2014. Lipochitooligosaccharide recognition: an ancient story. New Phytol 204:289-296. doi:10.1111/nph.12898

Limpens E, Franken C, Smit P, Willemse J, Bisseling T, Geurts R. 2003. LysM Domain Receptor Kinases Regulating Rhizobial Nod Factor-Induced Infection LysM Domain Receptor Kinases Regulating Rhizobial Nod Factor - Induced Infection. Science (80- ) 302:630-633. 
doi:10.1126/science.1090074

Lohmann GV, Shimoda Y, Nielsen MW, Jørgensen FG, Grossmann C, Sandal N, Sørensen K, Thirup S, Madsen LH, Tabata S, Sato S, Stougaard J, Radutoiu S. 2010. Evolution and Regulation of the Lotus japonicus LysM Receptor Gene Family. Mol Plant-Microbe Interact 23:510-521. doi:10.1094/MPMI-23-4-0510

Madsen EB, Madsen LH, Radutoiu S, Olbryt M, Rakwalska M, Szczyglowski K, Sato S, Kaneko T, Tabata S, Sandal N, Stougaard J. 2003. A receptor kinase gene of the LysM type is involved in legume perception of rhizobial signals. Nature 425:637-640. doi:10.1038/nature02045

Maekawa T, Kusakabe M, Shimoda Y, Sato S, Tabata S, Murooka Y, Hayashi M. 2008. Polyubiquitin Promoter-Based Binary Vectors for Overexpression and Gene Silencing in Lotus japonicus. Mol Plant-Microbe Interact 21:375-382. doi:10.1094/mpmi-21-4-0375

Maillet F, Poinsot V, André O, Puech-Pagès V, Haouy A, Gueunier M, Cromer L, Giraudet D, Formey D, Niebel A, Martinez EA, Driguez H, Bécard G, Dénarié J. 2011. Fungal lipochitooligosaccharide symbiotic signals in arbuscular mycorrhiza. Nature 469:58-63. doi:10.1038/nature09622

McAinsh MR, Hetherington AM. 1998. Encoding specificity in Ca2+ signalling systems. Trends Plant Sci 3:32-36. doi:10.1016/S1360-1385(97)01150-3

Mélida H, Sandoval-Sierra J V., Diéguez-Uribeondo J, Bulone V. 2013. Analyses of Extracellular Carbohydrates in Oomycetes Unveil the Existence of Three Different Cell Wall Types. Eukaryot Cell 12:194-203. doi:10.1128/ec.00288-12

Minami E, Kouchi H, Cohn JR, Ogawa T, Stacey G. 1996. Expression of the early nodulin, ENOD40, in soybean roots in response to various lipo-chitin signal molecules. Plant J 10:23-32. doi:10.1046/j.1365-313X.1996.10010023.x

Mithöfer A, Ebel J, Bhagwat AA, Boller T, Neuhaus-Url G. 1999. Transgenic aequorin monitors cytosolic calcium transients in soybean cells challenged with $\beta$-glucan or chitin elicitors. Planta 207:566-574. doi:10.1007/s004250050

Miwa H, Sun J, Oldroyd GED, Downie JA. 2006. Analysis of Nod-Factor-Induced Calcium Signaling in Root Hairs of Symbiotically Defective Mutants of Lotus japonicus. Mol Plant Microbe Interact 19:914-923. doi:10.1094/MPMI-19-0914

Miyawaki A, Llopis J, Heim R, McCaffery JM, Adams JA, Ikura M, Tsien RY. 1997. Fluorescent indicators for $\mathrm{Ca}^{2+}$ based on green fluorescent proteins and calmodulin. Nature 388:882-887. doi:10.1038/42264

Murakami E, Cheng J, Gysel K, Bozsoki Z, Kawaharada Y, Hjuler CT, Sørensen KK, Tao K, Kelly S, Venice F, Genre A, Thygesen MB, de Jong N, Vinther M, Jensen DB, Jensen KJ, Blaise M, Madsen LH, Andersen KR, Stougaard J, Radutoiu S. 2018. Epidermal LysM receptor ensures robust symbiotic signalling in Lotus japonicus. Elife 7:e33506. doi:10.7554/eLife.33506

Nars A, Lafitte C, Chabaud M, Drouillard S, Melida H, Danoun S, Le Costaouec T, Rey T, Benedetti 
J, Bulone V, Barker DG, Bono JJ, Dumas B, Jacquet C, Heux L, Fliegmann J, Bottin A. 2013. Aphanomyces euteiches Cell Wall Fractions Containing Novel Glucan-Chitosaccharides Induce Defense Genes and Nuclear Calcium Oscillations in the Plant Host Medicago truncatula. PLoS One 8:e75039. doi:10.1371/journal.pone.0075039

Navazio L, Moscatiello R, Genre A, Novero M, Baldan B, Bonfante P, Mariani P. 2007. A Diffusible Signal from Arbuscular Mycorrhizal Fungi Elicits a Transient Cytosolic Calcium Elevation in Host Plant Cells. Plant Physiol 144:673 LP - 681. doi:10.1104/pp.106.086959

Novero M, Faccio A, Genre A, Stougaard J, Webb KJ, Mulder L, Parniske M, Bonfante P. 2002. Dual requirement of the LjSym4 gene for mycorrhizal development in epidermal and cortical cells of Lotus japonicus roots. New Phytol 154:741-749. doi:10.1046/j.1469-8137.2002.00424.x

Papadopoulou K, Roussis A, Katinakis P. 1996. Phaseolus ENOD40 is involved in symbiotic and non-symbiotic organogenetic processes: Expression during nodule and lateral root development. Plant Mol Biol 30:403-417. doi:10.1007/BF00049320

Pappas ML, Liapoura M, Papantoniou D, Avramidou M, Kavroulakis N, Weinhold A, Broufas GD, Papadopoulou KK. 2018. The Beneficial Endophytic Fungus Fusarium solani Strain K Alters Tomato Responses Against Spider Mites to the Benefit of the Plant. Front Plant Sci 9:1603. doi:10.3389/fpls.2018.01603

Parniske M. 2008. Arbuscular mycorrhiza: the mother of plant root endosymbioses. Nat Rev Microbiol 6:763. doi:10.1038/nrmicro1987

Pfaffl MW. 2001. A new mathematical model for relative quantification in real-time RT-PCR. Nucleic Acids Res 29:e45. doi:10.1093/nar/29.9.e45

Radutoiu S, Madsen LH, Madsen EB, Felle HH, Umehara Y, Grønlund M, Sato S, Nakamura Y, Tabata S, Sandal N, Stougaard J. 2003. Plant recognition of symbiotic bacteria requires two LysM receptor-like kinases. Nature 425:585-592. doi:10.1038/nature02039

Ramakers C, Ruijter JM, Lekanne Deprez RH, Moorman AFM. 2003. Assumption-free analysis of quantitative real-time polymerase chain reaction (PCR) data. Neurosci Lett 339:62-66. doi:10.1016/S0304-3940(02)01423-4

Ramírez-Suero M, Khanshour A, Martinez Y, Rickauer M. 2010. A study on the susceptibility of the model legume plant Medicago truncatula to the soil-borne pathogen Fusarium oxysporum. Eur J Plant Pathol 126:517-530. doi:10.1007/s10658-009-9560-х

Rasmussen SR, Füchtbauer W, Novero M, Volpe V, Malkov N, Genre A, Bonfante P, Stougaard J, Radutoiu S. 2016. Intraradical colonization by arbuscular mycorrhizal fungi triggers induction of a lipochitooligosaccharide receptor. Sci Rep 6:1-12. doi:10.1038/srep29733

Russo G, Carotenuto G, Fiorilli V, Volpe V, Chiapello M, Van Damme D, Genre A. 2018. Ectopic activation of cortical cell division during the accommodation of arbuscular mycorrhizal fungi. New Phytol 221:1036-1048. doi:10.1111/nph.15398

Russo G, Spinella S, Sciacca E, Bonfante P, Genre A. 2013. Automated analysis of calcium spiking 
profiles with CaSA software: two case studies from root-microbe symbioses. BMC Plant Biol 13:224. doi:10.1186/1471-2229-13-224

Sanchez L, Weidmann S, Arnould C, Bernard AR, Gianinazzi S, Gianinazzi-Pearson V. 2005. Pseudomonas fluorescens and Glomus mosseae Trigger DMI3-Dependent Activation of Genes Related to a Signal Transduction Pathway in Roots of Medicago truncatula. Plant Physiol 139:1065 LP - 1077. doi:10.1104/pp.105.067603

Sanchez L, Weidmann S, Brechenmacher L, Batoux M, Van Tuinen D, Lemanceau P, Gianinazzi S, Gianinazzi-Pearson V. 2004. Common gene expression in Medicago truncatula roots in response to Pseudomonas fluorescens colonization, mycorrhiza development and nodulation. New Phytol 161:855-863. doi:10.1046/j.1469-8137.2004.00997.x

Schauser L, Handberg K, Sandal N, Stiller J, Thykjaer T, Pajuelo E, Nielsen A, Stougaard J. 1998. Symbiotic mutants deficient in nodule establishment identied after T-DNA transformation of Lotus japonicus. Mol Gen Genet 259:414-423.

Sieberer BJ, Chabaud M, Timmers AC, Monin A, Fournier J, Barker DG. 2009. A nuclear-targeted cameleon demonstrates intranuclear $\mathrm{Ca}^{2+}$ spiking in Medicago truncatula root hairs in response to rhizobial nodulation factors. Plant Physiol 151:1197-1206. doi:10.1104/pp.109.142851

Skiada V, Faccio A, Kavroulakis N, Genre A, Bonfante P, Papadopoulou KK. 2019. Colonization of Legumes by an Endophytic Fusarium solani strain FsK Reveals Common Features to Symbionts or Pathogens. Fungal Genet Biol 127:60-74. doi:10.1016/j.fgb.2019.03.003

Snyder WC, Hansen HN. 1940. The Species Concept in Fusarium. Am J Bot 27:64-67. doi:10.2307/2436688

Stacey G, Shibuya N. 1997. Chitin recognition in rice and legumes. Plant Soil 194:161-169. doi:10.1007/978-94-011-7113-7_16

Stracke S, Kistner C, Yoshida S, Mulder L, Sato S, Kaneko T, Tabata S, Sandal N, Stougaard J, Szczyglowski K, Parniske M. 2002. A plant receptor-like kinase required for both bacterial and fungal symbiosis. Nature 417:959-962. doi:10.1038/nature00841

Sun J, Miller JB, Granqvist E, Wiley-Kalil A, Gobbato E, Maillet F, Cottaz S, Samain E, Venkateshwaran M, Fort S, Morris RJ, Ané J-M, Dénarié J, Oldroyd GED. 2015. Activation of symbiosis signaling by arbuscular mycorrhizal fungi in legumes and rice. Plant Cell 27:823-38. doi:10.1105/tpc.114.131326

Svistoonoff S, Benabdoun FM, Nambiar-Veetil M, Imanishi L, Vaissayre V, Cesari S, Diagne N, Hocher V, de Billy F, Bonneau J, Wall L, Ykhlef N, Rosenberg C, Bogusz D, Franche C, Gherbi H. 2013. The Independent Acquisition of Plant Root Nitrogen-Fixing Symbiosis in Fabids Recruited the Same Genetic Pathway for Nodule Organogenesis. PLoS One 8:e64515. doi:10.1371/journal.pone.0064515

Takeda N, Okamoto S, Hayashi M, Murooka Y. 2005. Expression of LjENOD40 genes in response to symbiotic and non-symbiotic signals: LjENOD4O-1 and LjENOD4O-2 are differentially 
regulated in Lotus japonicus. Plant Cell Physiol 46:1291-1298. doi:10.1093/pcp/pci138

Tirichine L, Imaizumi-Anraku H, Yoshida S, Murakami Y, Madsen LH, Miwa H, Nakagawa T, Sandal N, Albrektsen AS, Kawaguchi M, Downie A, Sato S, Tabata S, Kouchi H, Parniske M, Kawasaki S, Stougaard J. 2006. Deregulation of a $\mathrm{Ca}^{2+} /$ calmodulin-dependent kinase leads to spontaneous nodule development. Nature 441:1153-6. doi:10.1038/nature04862

Vadassery J, Ranf S, Drzewiecki C, Mithofer A, Mazars C, Scheel D, Lee J, Oelmu R. 2009. A cell wall extract from the endophytic fungus Piriformospora indica promotes growth of Arabidopsis seedlings and induces intracellular calcium elevation in roots. Plant J 59:193-206. doi:10.1111/j.1365-313X.2009.03867.x

van de Wiel C, Scheres B, Franssen H, van Lierop MJ, van Lammeren A, van Kammen A, Bisseling T. 1990. The early nodulin transcript ENOD2 is located in the nodule parenchyma (inner cortex) of pea and soybean root nodules. EMBO J 9:1-7. doi:10.1002/j.1460-2075.1990.tb08073.x van der Luit AH, Olivari C, Haley A, Knight MR, Trewavas AJ. 1999. Distinct Calcium Signaling Pathways Regulate Calmodulin Gene Expression in Tobacco. Plant Physiol 121:705 LP - 714. doi:10.1104/pp.121.3.705

van Rhijn P, Fang Y, Galili S, Shaul O, Atzmon N, Wininger S, Eshed Y, Lum M, Li Y, To V, Fujishige N, Kapulnik Y, Hirsch AM. 1997. Expression of early nodulin genes in alfalfa mycorrhizae indicates that signal transduction pathways used in forming arbuscular mycorrhizae and Rhizobium-induced nodules may be conserved. Proc Natl Acad Sci U S A 94:5467-5472. doi:10.1073/pnas.94.10.5467

Verma S, Varma A, Rexer K, Hassel A, Kost G, Sarbhoy A, Bisen P, Butehorn B, Franken P. 1998. Piriformospora indica, gen. et sp. nov., a new root-colonizing fungus. Mycologia 90:896-903. doi:10.2307/3761331

Wais RJ, Galera C, Oldroyd G, Catoira R, Penmetsa R V, Cook D, Gough C, Denarié J, Long SR. 2000. Genetic analysis of calcium spiking responses in nodulation mutants of Medicago truncatula. Proc Natl Acad Sci U S A 97:13407-13412. doi:10.1073/pnas.230439797

Wang E, Schornack S, Marsh JF, Gobbato E, Schwessinger B, Eastmond P, Schultze M, Kamoun S, Oldroyd GED. 2012. A common signaling process that promotes mycorrhizal and oomycete colonization of plants. Curr Biol 22:2242-2246. doi:10.1016/j.cub.2012.09.043

Weerasinghe RR, Bird DM, Allen NS. 2005. Root-knot nematodes and bacterial Nod factors elicit common signal transduction events in Lotus japonicus. Proc Natl Acad Sci 102:3147-3152. doi:10.1073/pnas.0407926102

Wegel E, Schauser L, Sandal N, Stougaard J, Parniske M. 1998. Mycorrhiza Mutants of Lotus japonicus Define Genetically Independent Steps During Symbiotic Infection. Mol PlantMicrobe Interact 11:933-936. doi:10.1094/MPMI.1998.11.9.933

Yano K, Yoshida S, Mueller J, Singh S, Banba M, Vickers K, Markmann K, White C, Schuller B, Sato S, Asamizu E, Tabata S, Murooka Y, Perry J, Wang TL, Kawaguchi M, Imaizumi-Anraku 
H, Hayashi M, Parniske M. 2008. CYCLOPS, a mediator of symbiotic intracellular accommodation. Proc Natl Acad Sci U S A 105:20540-20545. doi:10.1073/pnas.0806858105 Zgadzaj R, James EK, Kelly S, Kawaharada Y, de Jonge N, Jensen DB, Madsen LH, Radutoiu S. 2015. A Legume Genetic Framework Controls Infection of Nodules by Symbiotic and Endophytic Bacteria. PLoS Genet 11:1-21. doi:10.1371/journal.pgen.1005280

Zgadzaj R, Thiergart T, Bozsoki Z, Garrido-Oter R, Radutoiu S, Schulze-Lefert P. 2019. Lotus japonicus symbiosis signaling genes and their role in the establishment of root-associated bacterial and fungal communities. bioRxiv $\mathbf{5 4 7 6 8 7 .}$

Zipfel C, Oldroyd GED. 2017. Plant signalling in symbiosis and immunity. Nature 543:328. doi:10.1038/nature22009 


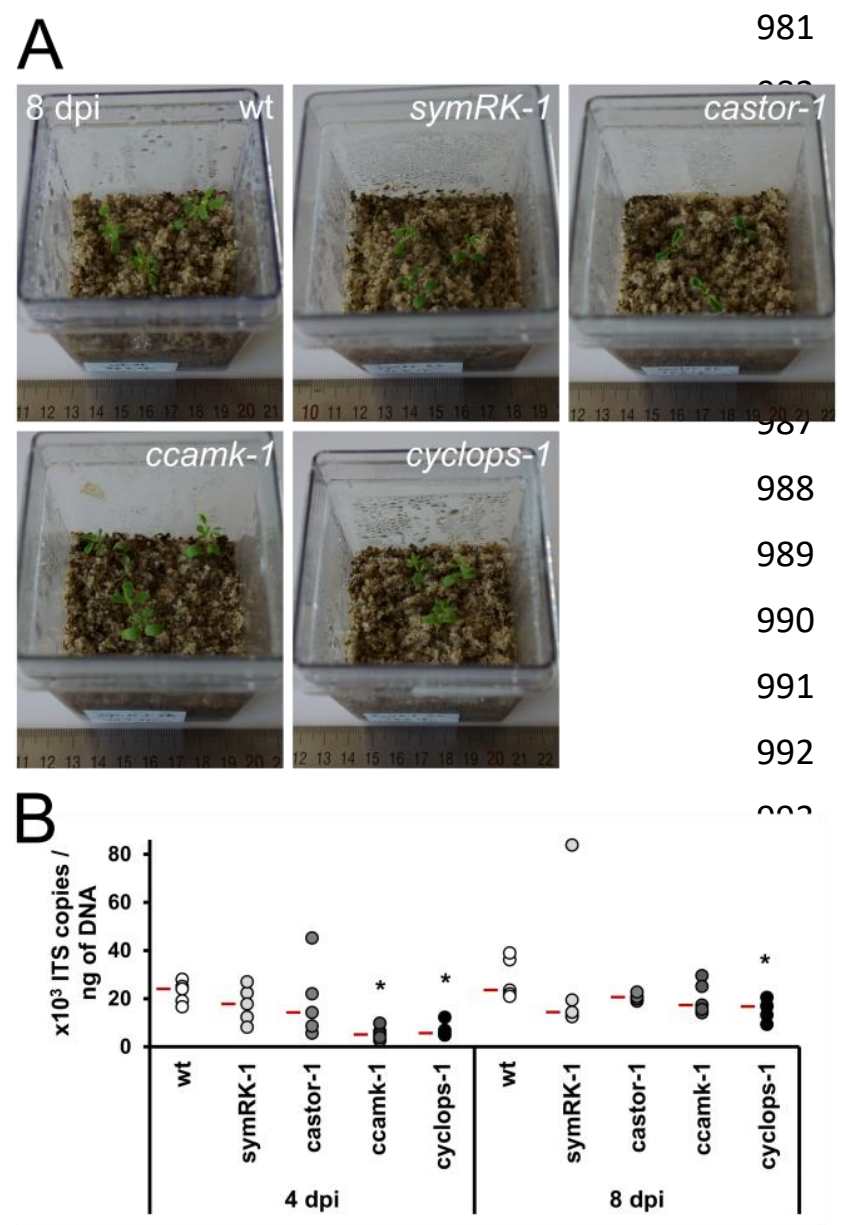

1000 Figure 1 Quantification of FsK colonization in L. japonicus CSSP mutants.

1001 A FsK inoculated Lotus japonicus wt and CSSP mutants at the last time point of the experiment ( $8 \mathrm{dpi}$ ).

1002 B Absolute quantification of FsK ingress within L. japonicus root tissues in wt and CSSP mutants 1003 (symRK-1, castor-1, ccamK-1, cyclops-1), via qPCR, using primers specific for a fragment of Fusarium 1004 ITS gene. Tissues were harvested at 4 and 8 dpi. ITS gene copy numbers are normalized to ng of total DNA extracted from the root tissue. Data are presented as a dotplot. Each dot represents a single biological replicate. 5 biological replicates were assessed for each genotype. Each replicate consists of 3 individual plants. Median values are presented in red. The experiment was repeated twice with similar results. 0.05 level (Student's t-test). 

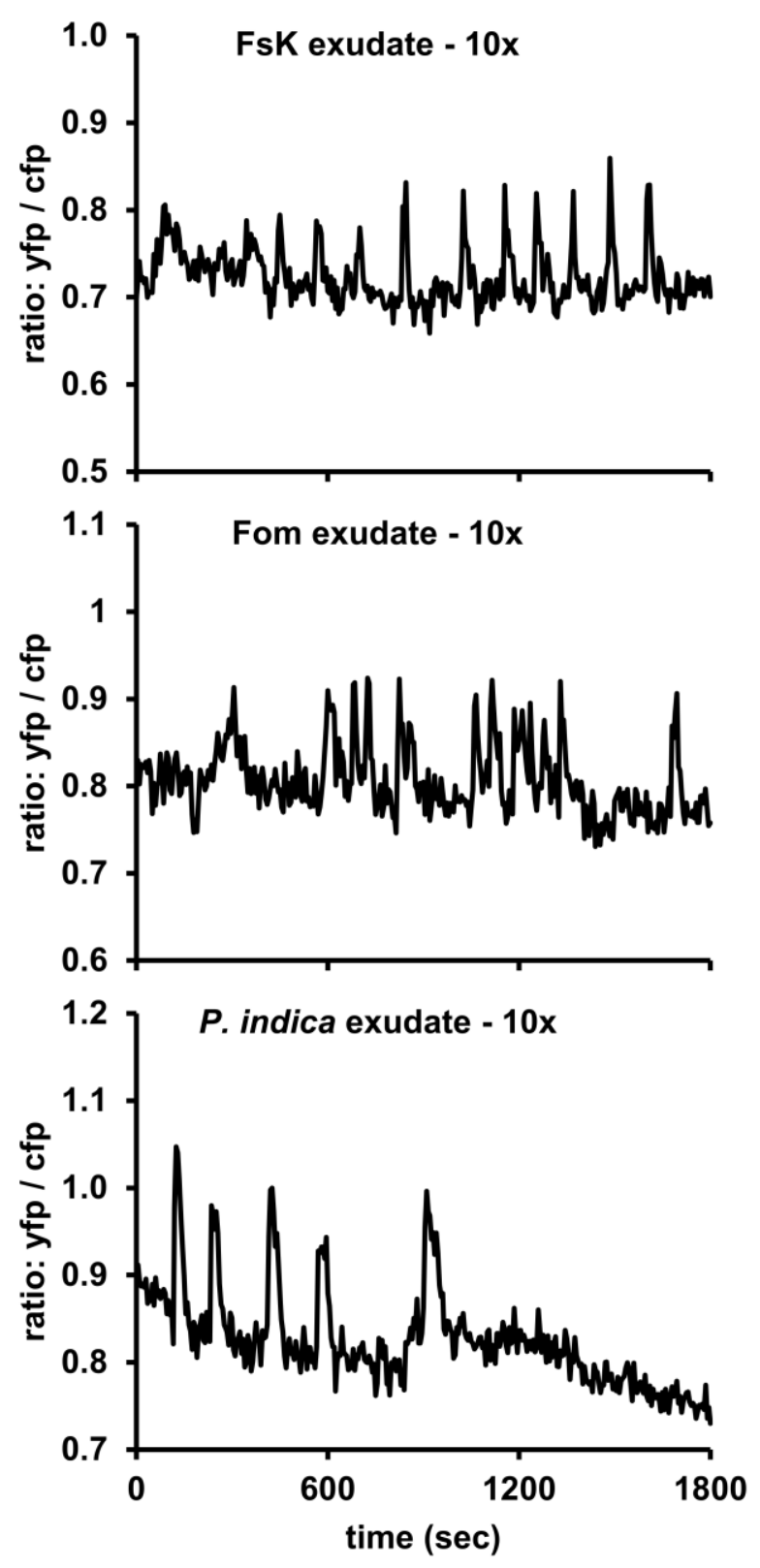

Figure 2 Exudates produced by fungi induce changes in nuclear calcium levels imaged using cameleon Mt ROCs.

Calcium spiking responses were recorded in a low-trichoblast-region located $10-20 \mathrm{~mm}$ from the root tip. M. truncatula wt ROCs expressing the NupYC2.1 cameleon were used for the bioassay. Fungal exudates derived from FsK, Fom, or $P$. indica were used as elicitors. Representative plots showing changes in nuclear calcium levels after treatment with 10x concentrated FsK, Fom, or $P$. indica exudate, in a $30 \mathrm{~min}(1800 \mathrm{sec})$ recording. Graphs show ratios of YFP:CFP fluorescence over time. The respective changes in fluorescence over time are presented in graphs of Supplementary Figure 2. 

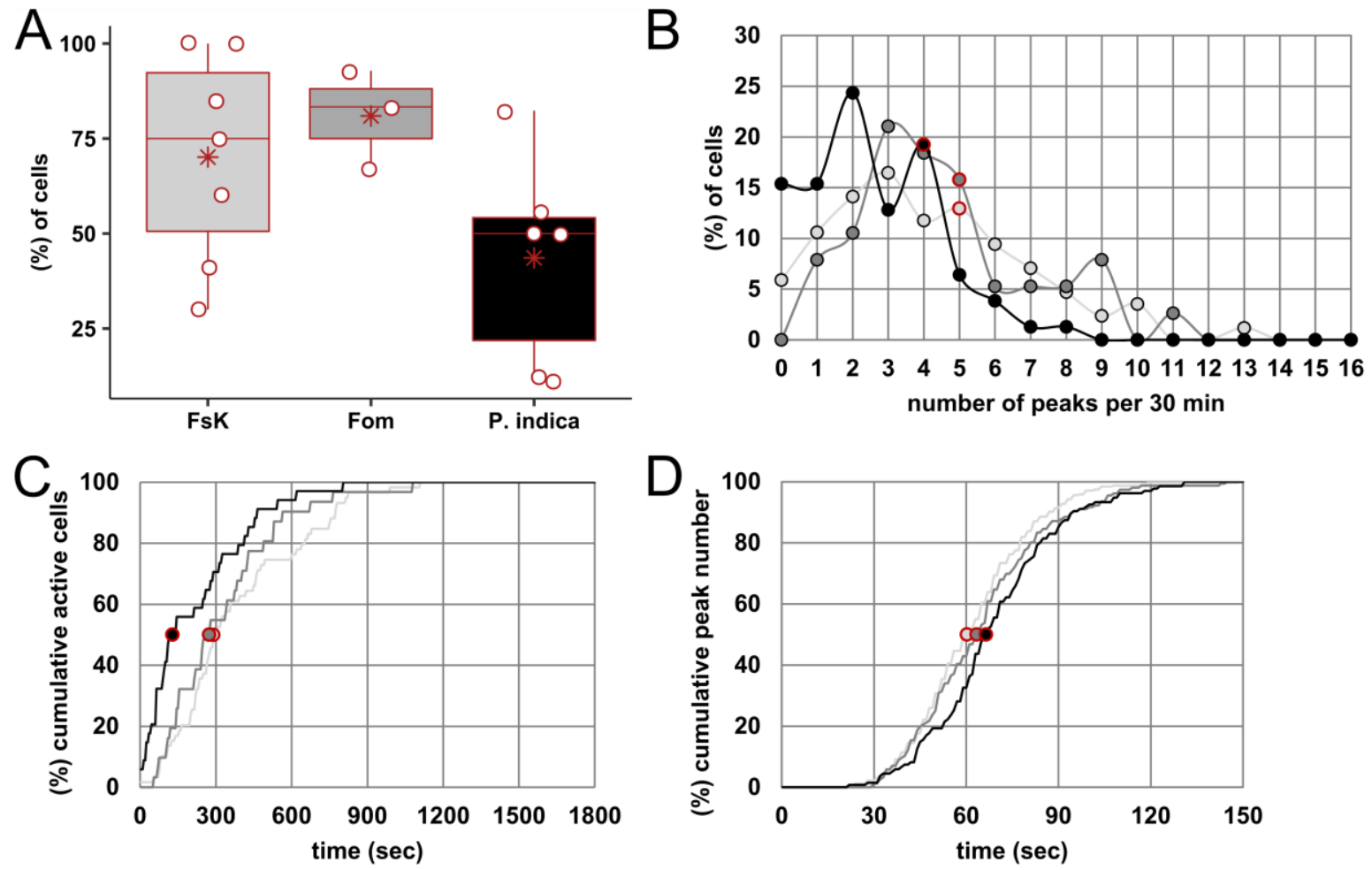

Figure 3 Analysis of fungal exudate-triggered nuclear calcium responses in $M t$ wt ROCs epidermis.

Calcium spiking responses were recorded in a low-trichoblast-region located $10-20 \mathrm{~mm}$ from the root tip. M. truncatula wt (ROCs) expressing the NupYC2.1 cameleon were used for the bioassay. Fungal exudates derived from FsK, Fom, or $P$. indica were used as elicitors.

A Percentage of responsive cells (peak number>2), in $30 \mathrm{~min}$ recordings post fungal exudate application. Data are presented as a dotplot in combination with a boxplot for each exudate. Each dot represents a single biological replicate (individual lateral root segments derived from ROCs). Median values are presented as red line within the boxplot, whereas average values are presented as a red asterisk. No statistically significant difference was recorded in average percentages of cells showing calcium spikes in response to FsK/FoM/P. indica exudate elicitation (one-way anova).

B Histogram exhibiting the distribution of fungal exudate-induced calcium spiking responses in all nuclei examined (active and non-active cells). Dots represent the frequency of peak number (presented in continuous intervals of 1 peak) in a 30 min recording period. Median peak number values calculated only in active cells are also presented in red.

Two-sample Kolmogorov Smirnov (K-S) test was performed to compare the distribution of peak numbers generated in response to the three exudates. Distributions were compared in a pairwise manner, under the null hypothesis that populations are drawn from the same distribution. When all cells (active and non-active) were included in the analysis: FsK- $P$. indica and Fom- $P$. indica comparison showed that data are drawn from different distributions ( $\mathrm{p}<0.005$ for both comparisons). 
C Cumulative probability line plots showing, for each exudate (depicted by different line colour), the percentage of active cells as functions of the delay time (in sec) recorded prior to spiking initiation. Lag phases were measured manually for all active nuclei examined per elicitor. Lag phase represents the time intervening between the recording initiation and the first recorded spike for each responsive nucleus. Median delay time values are also presented in red. Two-sample K-S test was then performed to compare the distribution of lag phases recorded in response to each elicitor. Distributions were compared in a pairwise manner, under the null hypothesis that populations are drawn from the same distribution. Pairwise comparisons among FsK- $P$. indica and Fom- $P$. indica showed that data are drawn from different distributions $(\mathrm{p}<0.005$ and $\mathrm{p}<0.05$, respectively).

1061 D Cumulative probability line plots showing, for each elicitor (depicted by different line colour), the percentage of active cells as functions of the spike width (in sec). Spike widths were measured manually for all peaks recorded and for each fungal exudate applied. Median spike width values are also presented

1064 in red.

1065 Two-sample K-S test was then performed to compare the distribution of spike width values recorded in response to each elicitor. Distributions were compared in a pairwise manner, under the null hypothesis that populations are drawn from the same distribution. Pairwise comparisons among FsK-P. indica showed that data are drawn from different distributions $(\mathrm{p}<0.005)$. calcium spiking responses, respectively. indicated in Supplementary Table 1. 

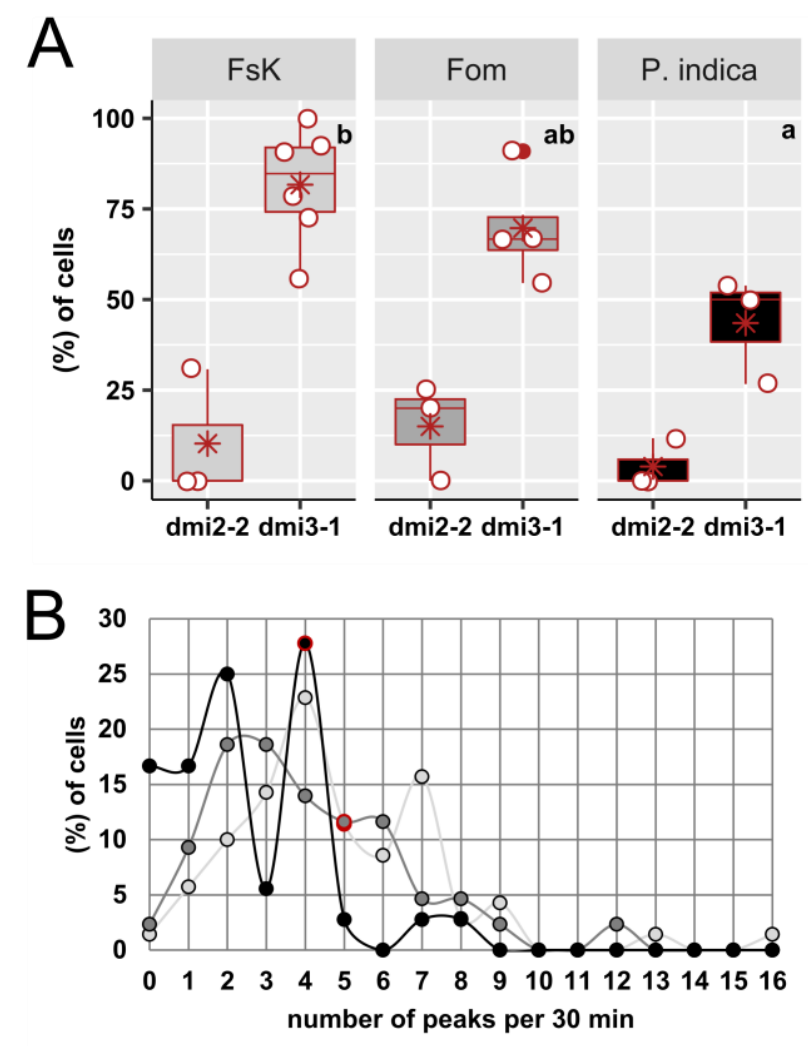

Figure 4 Analysis of fungal exudate-triggered nuclear calcium responses in $M t d m i 2-2$ and dmi3-1 ROCs epidermis.

Calcium spiking responses in a low-trichoblast-region located $10-20 \mathrm{~mm}$ from the root tip. $M$. truncatula dmi2-2 and dmi3-1 mutant lines (ROCs) expressing the NupYC2.1 cameleon were used for the bioassay. Fungal exudates derived from FsK, Fom, or $P$. indica were used as elicitors.

A Percentage of responsive cells (peak number>2) in the dmi2-2 and dmi3-1 mutant background, in 30 min recordings. Data are presented as a dotplot in combination with a boxplot for each mutant line/exudate. Each dot represents a single biological replicate (individual lateral root segments derived from ROCs). Median values are presented as red line within the boxplot, whereas average values are presented as a red asterisk. Note that an outlier is presented in dmi3-1 lines for Fom exudate (presented as a red dot). Outlier value was not removed from subsequent analysis as it was considered a result of biological variation.

1100 Different letters indicate statistically significant differences in percentages of $d m i 3-1$ responding cells to each elicitor (one-way Anova performed in biological replicates, followed by Tukey's post-hoc test). B Histogram exhibiting the distribution of fungal exudate-induced calcium spiking responses in nuclei of dmi3-1 ROC segments (active and non-active cells). Dots represent the frequency of peak number (presented in continuous intervals of 1 peak) in a 30 min recording period. Median peak number values calculated only in only active cells are presented in red.

1106 Two-sample (K-S) test was then performed to compare the distribution of peak numbers generated in response to fungal exudates. Distributions were compared in a pairwise manner, under the null 
1110 distributions $(\mathrm{p}<0.001)$.

1111 Light grey/dark grey/black lines: frequencies of peak number values of FsK/FoM/P. indica exudate-

1112 elicited calcium spiking responses in panel $\mathrm{B}$, respectively.

1113 The number of biological replicates/nuclei assessed for each elicitor/ROC line is indicated in

1114 Supplementary Table 1.

1115

1116

1117

1118

1119

1120 

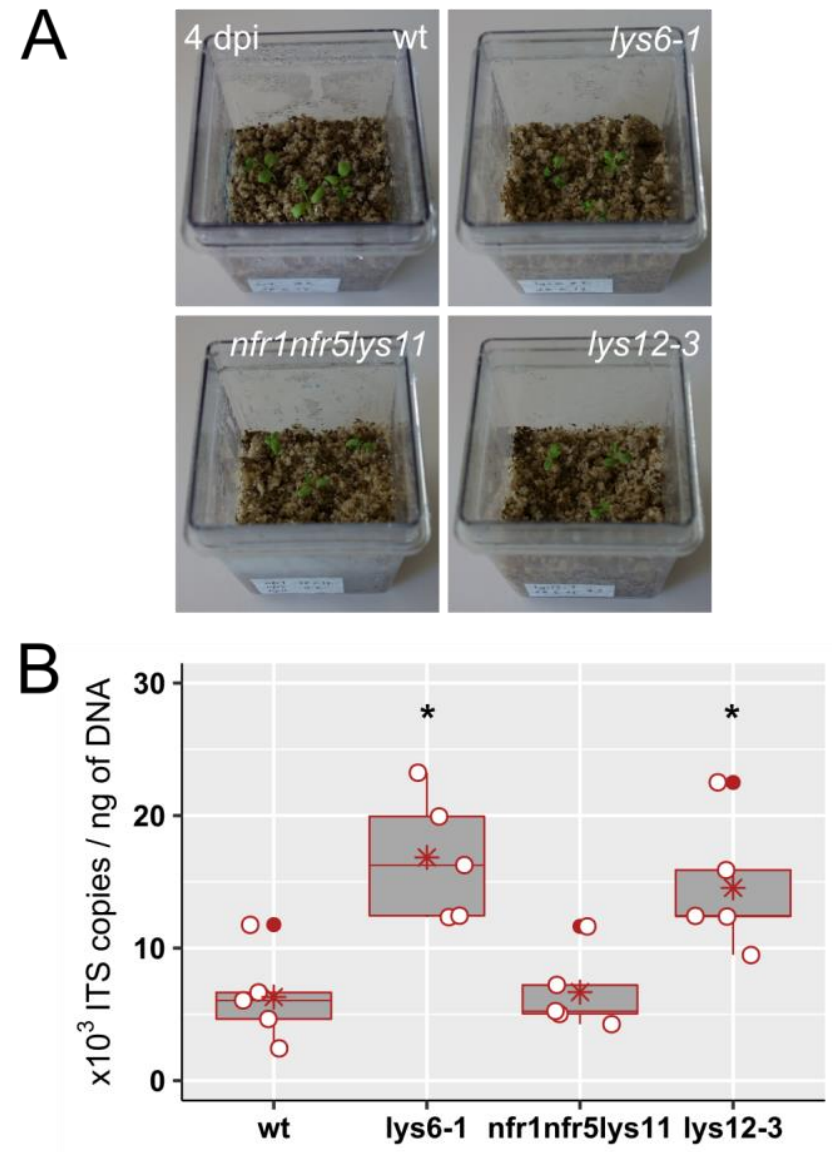

\section{C}

\section{Figure 5 Quantification of FsK abundance in roots of $L$. japonicus mutants impaired in LysM} receptors, and in LysM13/14 RNAi lines.

1149 A FsK inoculated L. japonicus wt and LysM mutants at the last time point of the experiment (4 dpi).

B Absolute quantification of FsK ingress within L. japonicus root tissues in wt and LysM mutants (lys61, nfrlnfr5lys11, lys12-3), via qPCR, using primers specific for a fragment of Fusarium ITS gene.

1152 Tissues were harvested at 4 dpi. ITS gene copy numbers are normalized to ng of total DNA extracted 1153 from wt and mutant root tissues, respectively. Data are presented as a dotplot. Each dot represents a

1154 single biological replicate. Median values are presented in red. 5 biological replicates were assessed for each genotype. Each replicate consists of 3 individual plants. 
Asterisks represent statistically significant differences between wt and the respective mutant lines at the

$1157 \quad 0.05$ level (Student's t-test).

1158 Note that there are outlier values in wt, nfrlnfr5lys11, and lys12-3 lines (presented as a red dot). Outlier

1159 values were not removed from subsequent analysis as they were considered a result of biological

1160 variation.

1161 C Absolute quantification of FsK abundance within control lines (presented as average values of 4 1162 independent plants) transformed with an empty T-DNA vector, and within 7 independent hairy root 1163 lines transformed with a Lys13/14 RNAi silencing construct (L3-L47). Quantification was performed 1164 via qPCR, using primers specific for a fragment of Fusarium TEF gene. Tissues were harvested at 5 1165 dpi. TEF gene copy numbers are normalized to ng of total DNA extracted from each root tissue sample. 1166 Data are presented as a dotplot. For the control, each dot represents a single biological replicate. Median 1167 value is presented in red. Each replicate consists of an individual plant. 4 independent plants were 1168 assessed. For the LysM13/14 RNAi lines, each dot represents the mean of 2 technical replicates.

1169 Mean FsK abundance value (average TEF gene copy numbers) of all Lys13/14 RNAi lines is 1170 significantly lower than that of controls at the 0.05 level (Student's t-test).

1171 The \% reduction in Lys 13 or Lys 14 relative transcript levels in RNAi lines in comparison to relative 1172 transcript levels in controls (as quantified via gene expression analysis; presented in Supplementary 1173 Figure 9) is presented at the lower part of the graph.

1174 n.r., no reduction in respective relative transcript levels. 